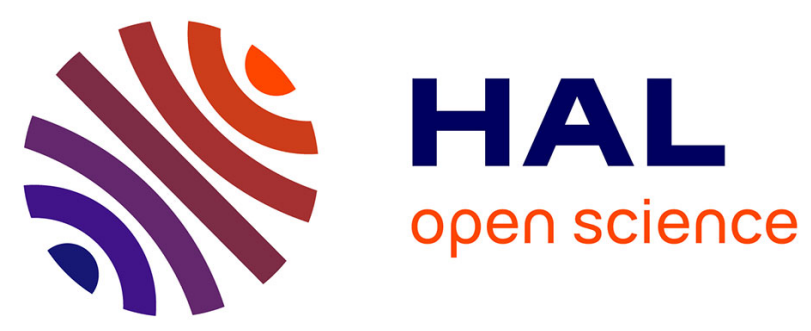

\title{
DFT investigations on the ring-opening polymerization of substituted cyclic carbonates catalyzed by zinc- $\beta$-diketiminate complexes
}

Iker Del rosal, Pierre Brignou, Sophie M. Guillaume, Jean-François

Carpentier, Laurent Maron

\section{To cite this version:}

Iker Del rosal, Pierre Brignou, Sophie M. Guillaume, Jean-François Carpentier, Laurent Maron. DFT investigations on the ring-opening polymerization of substituted cyclic carbonates catalyzed by zinc$\beta$-diketiminate complexes. Polymer Chemistry, 2015, 6 (17), pp.3336-3352. 10.1039/C5PY00313J . hal-01154160

\section{HAL Id: hal-01154160 \\ https://hal-univ-rennes1.archives-ouvertes.fr/hal-01154160}

Submitted on 16 Jun 2015

HAL is a multi-disciplinary open access archive for the deposit and dissemination of scientific research documents, whether they are published or not. The documents may come from teaching and research institutions in France or abroad, or from public or private research centers.
L'archive ouverte pluridisciplinaire HAL, est destinée au dépôt et à la diffusion de documents scientifiques de niveau recherche, publiés ou non, émanant des établissements d'enseignement et de recherche français ou étrangers, des laboratoires publics ou privés. 


\title{
DFT Investigations on the Ring-Opening Polymerization of
}

\section{Substituted Cyclic Carbonates Catalyzed by Zinc- $\{\beta$-Diketiminate $\}$ \\ Complexes}

Iker del Rosal ${ }^{1}$, Pierre Brignou ${ }^{2}$, Sophie M. Guillaume*2, Jean-François Carpentier*2, Laurent Maron*1

1. UMR5626 LPCNO (IRSAMC), Université de Toulouse, INSA and CNRS; 135 Avenue de Rangueil, F-31077 Toulouse, France

2. UMR 6226 Institut des Sciences Chimiques de Rennes, Université de Rennes 1 - CNRS, Organometallics, Materials and Catalysis laboratories, Campus de Beaulieu, 35042 Rennes Cedex, France

e-mail: sophie.guillaume@univ-rennes1.fr, jean-francois.carpentier@univ-rennes1.fr, laurent.maron@irsamc.ups-tlse.fr

\begin{abstract}
:
The ring-opening polymerizations of $\gamma$-methyl substituted six- and seven-membered ring cyclic carbonates, namely trimethylene carbonate (TMC- $\gamma \mathrm{Me})$ and the one-carbon larger homologue tetramethylene carbonate $(7 \mathrm{CC}-\gamma \mathrm{Me})$, using $\left[\left(\mathrm{BDI}^{\mathrm{iPr}}\right) \mathrm{Zn}\left(\mathrm{N}\left(\mathrm{SiMe}_{3}\right)_{2}\right)\right]\left(\mathrm{BDI}^{\mathrm{iPr}}=2-\right.$ ((2,6-diisopropylphenyl)amido)-4-((2,6-diisopropylphenyl)-imino)-2-pentene) as catalyst precursor, in the presence of benzyl alcohol $(\mathrm{BnOH})$ as initiator, have been investigated by means of density functional theory (DFT) calculations. This computational study highlights that the zinc-alkoxide catalyst obtained via alcoholysis of the $\mathrm{Zn}-\mathrm{N}$ bond of $\left[\left(\mathrm{BDI}^{\mathrm{iPr}}\right) \mathrm{Zn}\left(\mathrm{N}\left(\mathrm{SiMe}_{3}\right)_{2}\right)\right]$ by $\mathrm{HOBn}$, leading to the replacement of $\mathrm{N}\left(\mathrm{SiMe}_{3}\right)_{2}$ by an $-\mathrm{OBn}$ alkoxide with concomitant release of $\mathrm{HN}\left(\mathrm{SiMe}_{3}\right)_{2}$, is very active. For both TMC- $\gamma \mathrm{Me}$ and 1
\end{abstract}


7CC- $\gamma \mathrm{Me}$, the initiation and the propagation steps occur according to a three-step process: first, a nucleophilic attack of the alkoxide group followed by the ring-opening of the tetrahedral intermediate and finally the decoordination of the carbonate arm. In the methylsubstituted monomers, the presence of a stereogenic center and, more importantly, the dissymmetry of the monomer raise issues of the stereo- and regio-selectivity during the ROP process. In agreement with experimental results, for both carbonates, the relative Gibbs-free energies of the intermediates and the activation barriers involved in the ROP of both enantiomers $(R$ and $S)$ are very close, which is consistent with the formation of atactic polymers. In the same way, due to the presence of the $\gamma$-methyl substituent, two different products can be obtained upon cleavage of the acyl-oxygen bonds during the initiation step, and four different products during the propagation step. For both $7 \mathrm{CC}-\gamma \mathrm{Me}$ and TMC- $\gamma \mathrm{Me}$, computations indicate preferential ring-opening at the most hindered oxygen-acyl $\mathrm{O}_{1}-\mathrm{C}(\mathrm{O}) \mathrm{O}$ bond, i.e. the one closest to the Me substituent, in agreement with the regioselectivities experimentally observed. The relaxation of the steric constraints inside the growing polymer chain appears to be an important feature. From a thermodynamic point of view, the overall polymerization process is exergonic $(7 \mathrm{CC}-\gamma \mathrm{Me})$ or almost athermic (TMC- $\gamma \mathrm{Me})$, in agreement with the easier polymerizability of seven- vs. six-membered carbonate rings, as also observed with unsubstituted carbonates.

\section{Graphical Abstract}

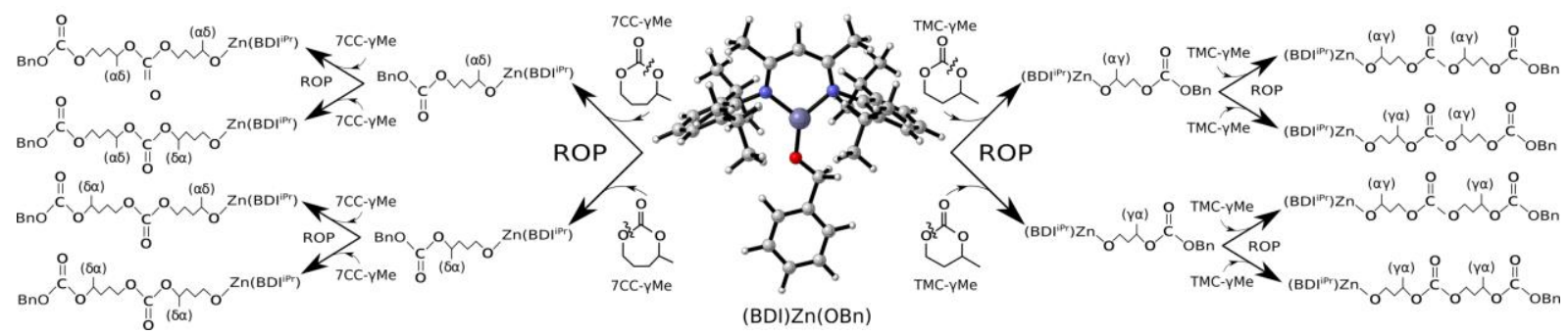




\section{Introduction}

Aliphatic polycarbonates have attracted much academic and industrial interest, especially over the last decade. Owing to their biocompatibility and biodegradation, this class of polymer has found applications in the biomedical and pharmaceutical domains. ${ }^{1}$ Aiming at green and environmentally friendly synthesis of polymers, efforts have been recently dedicated to develop polycarbonate materials from the biomass. ${ }^{2,3}$ In particular, glycerol, as well as bio-based acids such as levulinic or itaconic acids, have been valorised towards the preparation of (functionalized) cyclic carbonate monomers. Furthermore, in order to comply with specific targeted thermo-mechanical properties, and/or to enable vectorization of biologically active molecules, functionalization of carbonate and subsequently of polycarbonate structures is also highly desirable. ${ }^{4}$ Within this general context, we have been investigating the "immortal" ring-opening polymerization (iROP) of unsubstituted and substituted six- and seven-membered ring cyclic carbonates, namely the ubiquitous trimethylene carbonate (TMC) and the one-carbon larger homologue tetramethylene carbonate (7CC), along with their corresponding $\gamma$-methyl substituted analogues (TMC- $\gamma \mathrm{Me}$ and 7CC- $\gamma \mathrm{Me}$; Figure 1). ${ }^{5,6,7}$ In the latter methyl-substituted monomers, the presence of a stereogenic center and, more importantly, the dissymmetry of the monomer raise issues of the stereo-/regio-selectivity during the ROP process. In fact, microstructural analyses by ${ }^{1} \mathrm{H}$ and ${ }^{13} \mathrm{C}$ NMR spectroscopy of the polymers produced from the ROP of TMC- $\gamma \mathrm{Me}$ and $7 \mathrm{CC}-\gamma \mathrm{Me}$ mediated by the amido zinc $\beta$-diketiminate complex $\left[\left(\mathrm{BDI}^{\mathrm{iPr}}\right) \mathrm{Zn}\left(\mathrm{N}\left(\mathrm{SiMe}_{3}\right)_{2}\right)\right]\left(\mathrm{BDI}^{\mathrm{iPr}}=2-\right.$ ((2,6-diisopropylphenyl)amido)-4-((2,6-diisopropylphenyl)-imino)-2-pentene) revealed in both cases the preferential ring-opening at the most hindered oxygen-acyl $\mathrm{O}_{1}-\mathrm{C}(\mathrm{O}) \mathrm{O}$ bond, i.e. the one closest to the $\gamma$-Me substituent. ${ }^{6}$ In fact, due to the dissymmetry induced by the presence of the $\gamma$-methyl substituent, two different products can be obtained by the cleavage of the acyl-oxygen bonds (Figure 2). Cleavage of the most hindered oxygen-acyl $\mathrm{O}_{1}-\mathrm{C}(\mathrm{O})(\mathrm{O})$ bond leads to a growing polymer chain carrying a methyl group at the $\alpha$ position 
with respect to the oxygen atom coordinated to the metal centre and therefore in $\delta$ position of the oxygen atom of the carbonate ester group for 7CC- $\gamma \mathrm{Me}$, or respectively in $\alpha$ and $\gamma$ positions with respect to the same oxygen atoms for TMC- $\gamma \mathrm{Me}$. On the other hand, cleavage on the less hindered oxygen-acyl $\mathrm{O}_{2}-\mathrm{C}(\mathrm{O})(\mathrm{O})$ bond leads to a growing polymer chain carrying a methyl group at the $\delta$ position with respect to the oxygen atom coordinated to the metal centre and therefore in $\alpha$ position of the oxygen atom of the carbonate ester for 7CC$\gamma \mathrm{Me}$, or respectively in $\gamma$ and $\alpha$ positions with respect to the same oxygen atoms for TMC$\gamma \mathrm{Me}$. This nomenclature has been used in the following.

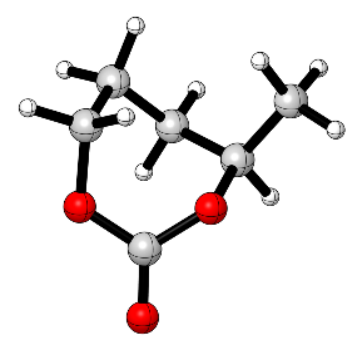

(a) (R)-7CC- $\gamma \mathrm{Me}$

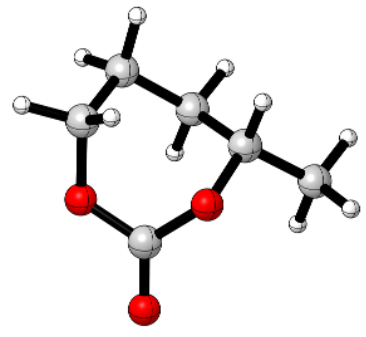

(b) $(S)-7 \mathrm{CC}-\gamma \mathrm{Me}$

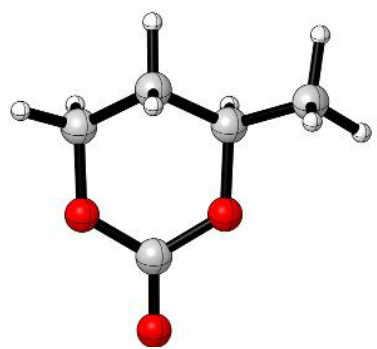

(c) $($ R)-TMC- $\gamma \mathrm{Me}$

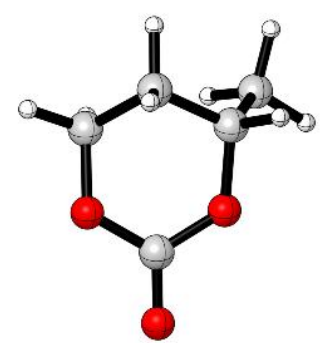

(d) $(S)$-TMC- $\gamma \mathrm{Me}$

Figure 1. Optimized structures of the two enantiomers of $\alpha$-methyl-substituted trimethylene (TMC- $\gamma \mathrm{Me})$ and tetramethylene (7CC- $\gamma \mathrm{Me})$ carbonates.

Combination of experimental and computational investigations allows getting deeper insights and understanding into the ROP mechanism of unsubstituted TMC and 7CC mediated by $\left[\left(\mathrm{BDI}^{\mathrm{iPr}}\right) \mathrm{Zn}\left(\mathrm{N}\left(\mathrm{SiMe}_{3}\right)_{2}\right)\right] .{ }^{8}$ The present DFT study evaluates the contribution of a "simple" $\gamma$-alkyl substituent, namely a $\gamma$-methyl, onto a TMC or 7CC frame, on the energetics of the ROP mechanism mediated by zinc $\beta$-diketiminate complexes $\left[\left(\mathrm{BDI}^{\mathrm{iPr}}\right) \mathrm{ZnX}\right]$ with $\mathrm{X}=$ $\mathrm{N}\left(\mathrm{SiMe}_{3}\right)_{2}, \mathrm{OMe}, \mathrm{OCH}_{2} \mathrm{Ph}(\mathrm{OBn})$, from in silico insights and in light of the experimental data we previously reported..$^{5,6,7,8}$ 


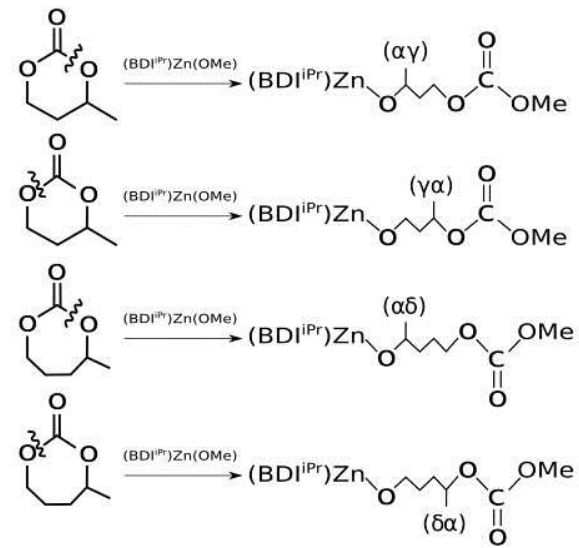

Figure 2. Possible regioselectivities for the ROP of TMC- $\gamma \mathrm{Me}$ and $7 \mathrm{CC}-\gamma \mathrm{Me}$.

\section{Methodological Details}

All calculations were performed with Gaussian $03 .{ }^{9}$ Calculations were carried out at the DFT level of theory using the hybrid functional B3PW91. ${ }^{10}$ Geometry optimizations were achieved without any symmetry restriction. Calculations of vibrational frequencies were systematically done in order to characterize the nature of stationary points. Stuttgart effective core potentials ${ }^{11}$ and their associated basis set were used for zinc. Silicon, nitrogen, hydrogen, carbon and oxygen atoms were treated with $6-31 \mathrm{G}(\mathrm{d}, \mathrm{p})$ double- $\zeta$ basis sets. ${ }^{12}$ The electron density and partial charge distribution were examined in terms of localized electron-pair bonding units by using the NBO program implemented in Gaussian $03 .{ }^{13}$ ROP reactions of those cyclic carbonate monomers have been experimentally conducted either in neat monomer or in toluene solution (both leading to quite similar results), that is with the same solvent in which the monomeric (mononuclearity) nature of the initiator species was established. Here, computations have been carried out in the gas phase, which is reasonable considering that toluene was not previously shown to interact with the active species.

\section{Results and Discussion}

The ROP of a cyclic carbonate initiated by $\left[\left(\mathrm{BDI}^{\mathrm{iPr}}\right) \mathrm{Zn}\left(\mathrm{N}\left(\mathrm{SiMe}_{3}\right)_{2}\right)\right]$, possibly combined with an alcohol as a co-initiator/chain transfer agent,${ }^{5}$ is assumed to proceed via a 
coordination-insertion mechanism. ${ }^{5,14}$ This latter route involves three steps. First, the "active" function $\left(\mathrm{X}=\mathrm{N}\left(\mathrm{SiMe}_{3}\right)_{2}\right.$ or an alkoxide initiator generated in situ, vide infra) performs a nucleophilic attack onto the activated carbonyl group of the coordinated monomer ${ }^{15}$. This reaction is followed by the cleavage of the oxygen-acyl bond, i.e., a spontaneous ringopening with the concomitant decoordination of the carbonate arm from the metal centre. In a previous work, we have demonstrated, based on the study of the reactivity of the zinc amido precursor, that the successful ROP of cyclic esters mediated by $\left[\left(\mathrm{BDI}^{\mathrm{Pr}}\right) \mathrm{Zn}\left(\mathrm{N}\left(\mathrm{SiMe}_{3}\right)_{2}\right)\right] / \mathrm{ROH}$ (Figure 3a) originates from the in situ formation of an active alkoxide species, $\left[\left(\mathrm{BDI}^{\mathrm{iPr}}\right) \mathrm{Zn}(\mathrm{OR})\right]$ (Figures 3b-c). ${ }^{8}$ Indeed, the high energetic cost of the nucleophilic attack step found with the zinc amido precursor indicates that the ROP reaction cannot be mediated by this species. In the same study, we have also shown that the $\left[\left(\mathrm{BDI}^{\mathrm{iPr}}\right) \mathrm{Zn}(\mathrm{OBn})\right]$ complex can be safely simplified for DFT computations upon replacing the benzyloxy (Figure 3c) by a methoxy moiety (Figure 3b). This modelling strategy was found not to alter either the nucleophilic character of the alkoxide ligand or the structure of the zinc complex, thus suggesting that it should not affect the reactivity of the complex. Therefore, in order to save some computational time, the following discussion is limited to the use of the zinc methoxide initiating species in the ROP of the TMC- $\gamma \mathrm{Me}$ and 7CC- $\gamma \mathrm{Me}$ cyclic esters. Similarly, for the sake of clarity, the study of the ROP reaction of those cyclic carbonates promoted by $\left[\left(\mathrm{BDI}^{\mathrm{iPr}}\right) \mathrm{Zn}(\mathrm{OMe})\right]$ is analysed separately in the following subsections. The ROP mechanism of $7 \mathrm{CC}-\gamma \mathrm{Me}$ is first discussed, followed by that of TMC- $\gamma \mathrm{Me}$. Note that the last termination/deactivation step has not been investigated since end-capping of the recovered polymer by the alkoxide $\left(\mathrm{OR}^{-}, \mathrm{R}=\mathrm{Bn}, \mathrm{Me}\right)$ is expected. ${ }^{16}$ 


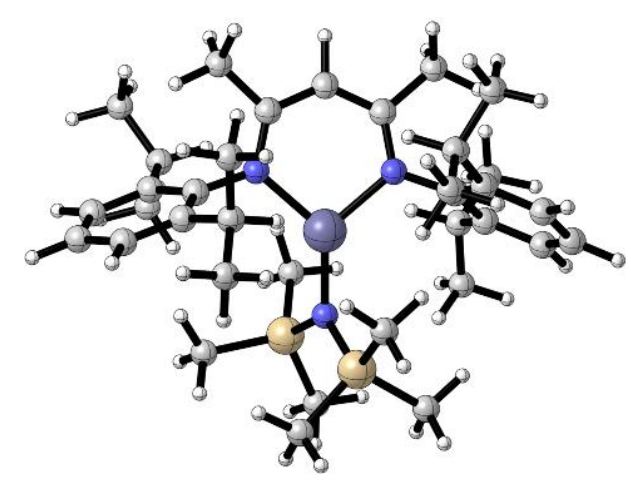

a) $\left[\left(\mathrm{BDI}^{\mathrm{iPr}}\right) \mathrm{Zn}\left(\mathrm{N}\left(\mathrm{SiMe}_{3}\right)_{2}\right)\right]$

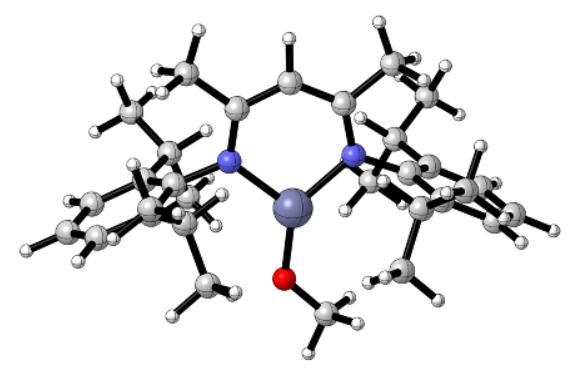

c) $\left[\left(\mathrm{BDI}^{\mathrm{iPr}}\right) \mathrm{Zn}(\mathrm{OMe})\right]$

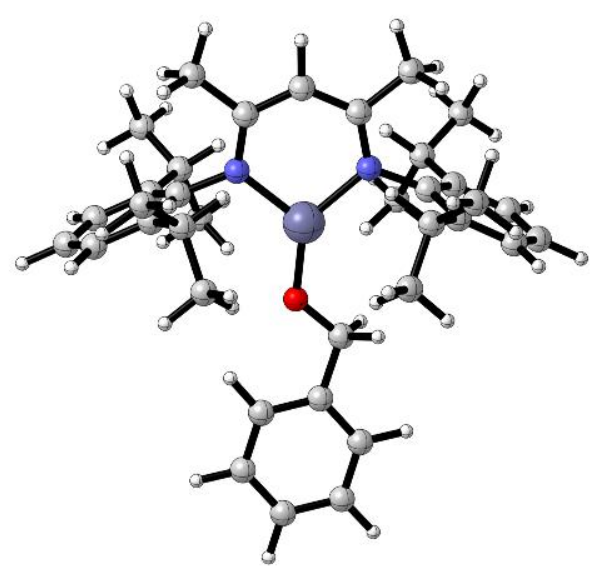

b) $\left[\left(\mathrm{BDI}^{\mathrm{iPr}}\right) \mathrm{Zn}(\mathrm{OBn})\right]$

Figure 3. Optimized structures of the $\left[\left(\mathrm{BDI}^{\mathrm{iPr}}\right) \mathrm{Zn}\left(\mathrm{N}\left(\mathrm{SiMe}_{3}\right)_{2}\right)\right]$ precursor, the real active species $\left[\left(\mathrm{BDI}^{\mathrm{iPr}}\right) \mathrm{Zn}(\mathrm{OBn})\right]$, and the simplified model $\left[\left(\mathrm{BDI}^{\mathrm{iPr}}\right) \mathrm{Zn}(\mathrm{OMe})\right]$ complex.

\subsection{Ring-opening polymerization of $\alpha$-methyl-substituted tetramethylene carbonate}

\section{Initiation Step of the ROP of 7CC- $\gamma \mathrm{Me}$.}

The gamma substitution of one hydrogen atom by a methyl group induces two enantiomeric $(R)$ - and $(S)$-7CC- $\gamma$ Me compounds (Figures 1a-b). Because of the prochirality of the carbon atom of the $\mathrm{C}=\mathrm{O}$ group, two different enantiofaces, $r e$ and $s i$, are identified in the $(R)$ - and $(S)$-7CC- $\gamma \mathrm{Me}$ monomers, which are hereafter referred to as 7CC- $\gamma(R, r e)$, 7CC$\gamma(R, s i), 7 \mathrm{CC}-\gamma(S, r e)$ and $7 \mathrm{CC}-\gamma(S, s i)$, respectively (Figure 4). For the sake of a tractable analysis, the study of the ROP of both enantiomers is delineated separately (starting with the (R)-7CC- $\gamma \mathrm{Me}$ enantiomer). For each $r e$ and si enantioface, the initiation step of the ROP of 7CC- $\gamma(R)$ mediated by $\left[\left(\mathrm{BDI}^{\mathrm{iPr}}\right) \mathrm{Zn}(\mathrm{OMe})\right]$ has been computed. 


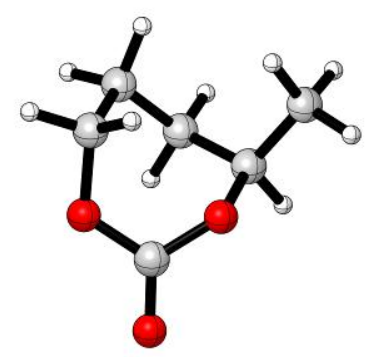

(a) $7 \mathrm{CC}-\gamma(\boldsymbol{R}, r e)$

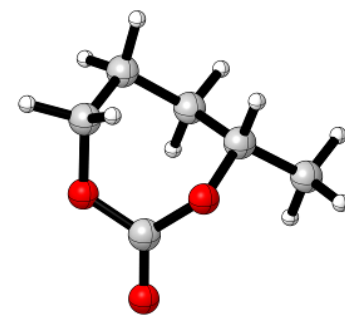

(b) $7 \mathrm{CC}-\gamma(S, r e)$

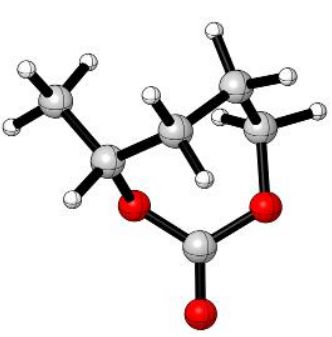

(c) $7 \mathrm{CC}-\gamma(R, s i)$

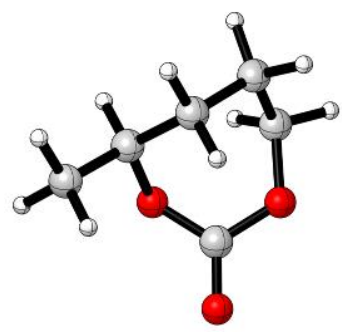

(d) $7 \mathrm{CC}-\gamma(S, s i)$

Figure 4. Representation of the $r e$ and si enantiofaces of $(R)$ - and $(S)$-7CC- $\gamma$ Me monomers.

The free Gibbs energy profile of the initiation step of the ROP of 7CC- $\gamma(R, r e)$ is depicted in Figure 5. A view of the different transition states and intermediates is available in Figures 6 and 7 and the key geometrical parameters are summarized in Table S1. The reaction begins by the formation of an endergonic $\mathbf{I}_{7 \mathrm{CC}-\gamma(R, r e)}$ adduct (Figure 6a) with a Gibbs-free energy of $11.8 \mathrm{kcal} . \mathrm{mol}^{-1}$ with respect to the entrance channel, which corresponds to the loss

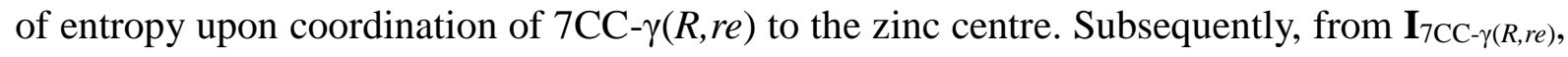
the nucleophilic attack of the methoxy group onto the carbonyl carbon $\mathrm{C}_{\mathrm{CO}}$ of the re enantioface of $7 \mathrm{CC}-\gamma(R)$ takes place via transition state $\operatorname{TS}\left(\mathbf{I}_{7 \mathrm{CC}-\gamma(R, r e)} \rightarrow \mathbf{I I}^{\delta \alpha}{ }_{7 \mathrm{CC}-\gamma(R, r e)}\right.$ ) (Figure $6 b)$, yielding a second intermediate $\mathbf{I I}^{\delta \alpha} 7 \mathrm{CC}-\gamma(R, r e)$ (Figure $6 \mathrm{c}$ ). The activation energy for this

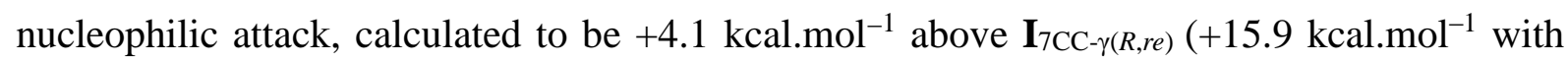
respect to the entrance channel), corresponds to a kinetically accessible process. The formation of $\mathbf{I I}^{\delta \alpha} 7 \mathrm{CC}-\gamma(R, r e)$ is found to be endergonic with respect to the separated reactants $\left(+5.8 \mathrm{kcal} . \mathrm{mol}^{-1}\right)$ but slightly exergonic $\left(-6.0 \mathrm{kcal} . \mathrm{mol}^{-1}\right)$ with respect to adduct $\mathbf{I}_{7 \mathrm{CC}-\gamma(R, r e)}$. From a geometrical point of view, for $\operatorname{TS}\left(\mathbf{I}_{7 \mathrm{CC}-\gamma(R, r e)} \rightarrow \mathbf{I I}^{\delta \alpha}{ }_{7 \mathrm{CC}-\gamma(R, r e)}\right)$, a pyramidalization of the $\mathrm{C}_{\mathrm{C}=\mathrm{O}}$ carbon $\left(355^{\circ}\right)$ is observed, i.e., a rehybridization from $\mathrm{sp}^{2}$ to $\mathrm{sp}^{3}$ of $\mathrm{C}_{\mathrm{C}=\mathrm{O}}$, so that the resulting $\mathrm{sp}^{3}$ acceptor orbital points towards the oxygen atom of the methoxy group leading to the formation of a $\mathrm{C}_{\mathrm{CO}}-\mathrm{O}_{\mathrm{OMe}}$ single bond in $\mathbf{I I}^{\delta \alpha}{ }_{7 \mathrm{CC}-\gamma(R, r e)}$. At $\mathbf{I I}^{\delta \alpha}{ }_{7 \mathrm{CC}-\gamma(R, r e)}$, the $\mathrm{Zn}-\mathrm{O}_{\mathrm{CO}}$ distance is shortened compared to $\mathbf{I}_{7 \mathrm{CC}-\gamma(R, r e)}$ and the $\mathrm{C}_{\mathrm{CO}}-\mathrm{O}_{\mathrm{CO}}$ distance is elongated, which is coherent with the presence of a single bond between $\mathrm{C}_{\mathrm{CO}}$ and $\mathrm{O}_{\mathrm{CO}}$. It is also noteworthy that, compared 
to $\mathbf{I}_{7 \mathrm{CC}-\gamma(R, r e)}$, the $\mathrm{Zn}-\mathrm{O}_{1}$ distance $\left(\mathrm{O}_{1}\right.$ corresponding to the endocyclic oxygen atom in $\alpha$ position with respect to the substituted $\mathrm{C}_{\mathrm{Me}}$ atom; see Figure 2) is elongated, while the $\mathrm{Zn}-\mathrm{O}_{2}$ distance $\left(\mathrm{O}_{2}\right.$ corresponding to the farthest endocyclic oxygen atom with respect to the substituted $\mathrm{C}_{\mathrm{Me}}$ atom) is shortened. The second-order perturbation NBO analysis revealed the presence of a stabilizing interaction between the endocyclic oxygen atom $\mathrm{O}_{2}$ and the metal centre (donation from a lone pair of the oxygen atom towards an empty $p$ orbital of zinc).

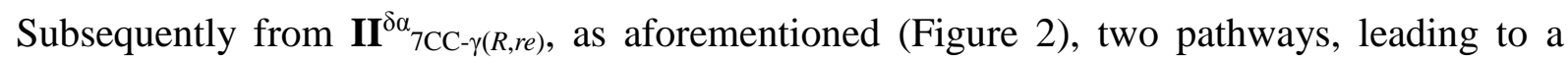
growing polymer chain carrying a methyl group at the $\delta$ position with respect to the oxygen atom coordinated to the metal centre and therefore in $\alpha$ position of the oxygen atom of the carbonate ester group $\left(\mathbf{I V}^{\delta \alpha}{ }_{7 \mathrm{CC}-\gamma(R)}\right.$, Figure $\left.7 \mathrm{~d}\right)$, or conversely in $\alpha$ and $\delta$ position with respect to the same oxygen atoms $\left(\mathbf{I V}^{\alpha \delta_{7 C C}-\gamma(R)}\right.$, Figure $\left.7 \mathbf{j}\right)$, are possible. The formation of $\mathbf{I V}{ }^{\delta \alpha}{ }_{7 \mathrm{CC}-\gamma(R)}$, from $\mathbf{I I}^{\delta \alpha}{ }_{7 \mathrm{CC}-\gamma(R, r e)}$, involves the transition state $\operatorname{TS}\left(\mathbf{I I}^{\delta \alpha}{ }_{7 \mathrm{CC}-\gamma(R, r e)} \rightarrow \mathbf{I I I}^{\delta \alpha}{ }_{7 \mathrm{CC}-\gamma(R, r e)}\right)$ (Figure $\left.7 \mathrm{a}\right)$ which lies $8.5 \mathrm{kcal} . \mathrm{mol}^{-1}$ above $\mathbf{I I}^{\delta \alpha}{ }_{7 \mathrm{CC}-\gamma(R, r e)}\left(+14.3 \mathrm{kcal} \cdot \mathrm{mol}^{-1}\right.$ above to the separated reactants). This transition state corresponds to the cleavage of the acyl- $\mathrm{O}_{2}$ bond, i.e., a spontaneous ring-opening of the $7 \mathrm{CC}-\gamma(R, r e)$ cycle. Following the intrinsic reaction coordinate, $\quad \operatorname{TS}\left(\mathbf{I I}^{\delta \alpha}{ }_{7 \mathrm{CC}-\gamma(R, r e)} \rightarrow \mathbf{I I I}^{\delta \alpha}{ }_{7 \mathrm{CC}-\gamma(R, r e)}\right)$ leads to the thermodynamically unstable

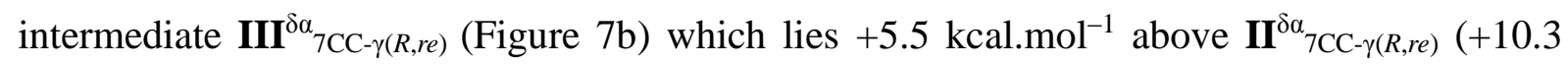
kcal.mol ${ }^{-1}$ with respect to the entrance channel). In this intermediate, the $\gamma$-substituted 7CC ring is completely opened $\left(\mathrm{C}_{\mathrm{CO}}-\mathrm{O}_{2}=2.57 \AA\right)$. The $\mathrm{C}_{\mathrm{CO}}-\mathrm{O}_{\mathrm{CO}}$ distance is also shortened, which highlights the relocalisation of a double bond between these two atoms. The $\mathrm{Zn}-\mathrm{O}_{2}$ distance is also shortened while the $\mathrm{Zn}-\mathrm{O}_{\mathrm{CO}}$ distance is elongated, which indicates that the intracyclic oxygen atom ensures the coordination to the metal centre. The last step concerns the relaxation of the growing polymer chain that essentially consists in the decoordination of the carbonate arm. This process takes place through the transition state $\mathrm{TS}\left(\mathbf{I I I}^{\delta \alpha}{ }_{7 \mathrm{CC}}\right.$ $\gamma(R, r e) \rightarrow \mathbf{I} \mathbf{V}^{\delta \alpha_{7 C C}-\gamma(R)}$ ) (Figure 7c), leading to the final slightly exergonic $\mathbf{I V}^{\delta \alpha{ }_{7 C C}-\gamma(R)}$ product, with a Gibbs-free energy of $-1.0 \mathrm{kcal} . \mathrm{mol}^{-1}$ with respect to the entrance channel. The 
decoordination of the carbonate arm occurs via a low energy process with an activation barrier calculated to be $+0.4 \mathrm{kcal} . \mathrm{mol}^{-1}$ with respect to $\mathbf{I I I}^{\delta \alpha}{ }_{7 \mathrm{CC}-\gamma(R, r e)}\left(+10.7 \mathrm{kcal}^{\mathrm{mol}}{ }^{-1}\right.$ with

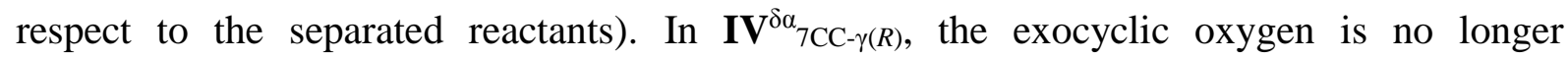
interacting with the metal center and the coordination of the carbonate ester arm to the metal centre is ensured by the endocyclic oxygen $\mathrm{O}_{2}$. Therefore, the nucleophilic attack is, as observed above, the rate-determining step of an overall facile reaction.

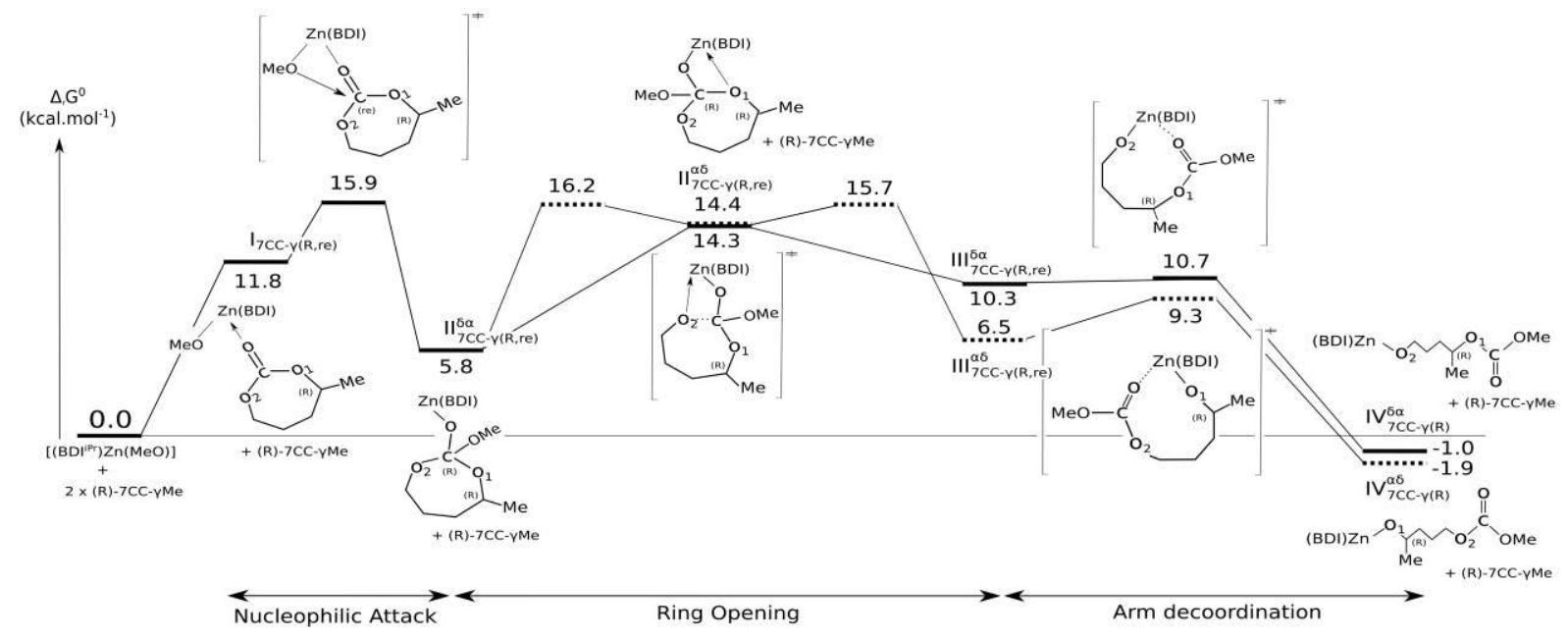

Figure 5. Calculated free-energy profile of the initiation step of the ROP of 7CC- $\gamma(R, r e)$ mediated by $\left[\left(\mathrm{BDI}^{\mathrm{iPr}}\right) \mathrm{Zn}(\mathrm{OMe})\right]$. In order to differentiate the two alkoxy oxygen atoms of the carbonate ester functional group, the oxygen atom closest to the substituted carbon atom is labelled $\mathrm{O}_{1}$; the other oxygen atom is then labelled $\mathrm{O}_{2}$.

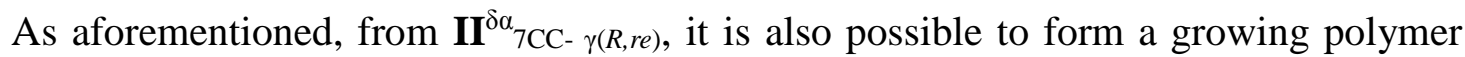
chain carrying a methyl group in $\alpha \delta$ position $\left(\mathbf{I} \mathbf{V}^{\alpha \delta}{ }_{7 \mathrm{CC}-\gamma(R)}\right)$. The formation of this alternative growing polymer chain results from the tilting of the $7 \mathrm{CC}-\gamma(R, r e)$ monomer which leads to the $\mathrm{Zn}-\mathrm{O}_{1}$ interaction and to the loss of the $\mathrm{Zn}-\mathrm{O}_{2}$ interaction. The tilting reaction takes place via transition state $\operatorname{TS}\left(\mathbf{I I}^{\delta \alpha}{ }_{7 \mathrm{CC}-\gamma(R, r e)} \rightarrow \mathbf{I I}^{\alpha \delta}{ }_{7 \mathrm{CC}-\gamma(R, r e)}\right)$ (Figure 7e). The activation energy for this step is calculated to be $+10.4 \mathrm{kcal} . \mathrm{mol}^{-1}$ above $\mathbf{I I}^{\delta \alpha}{ }_{7 \mathrm{CC}-\gamma(R, r e)}\left(+16.2 \mathrm{kcal} . \mathrm{mol}^{-1}\right.$ above the entrance channel). 


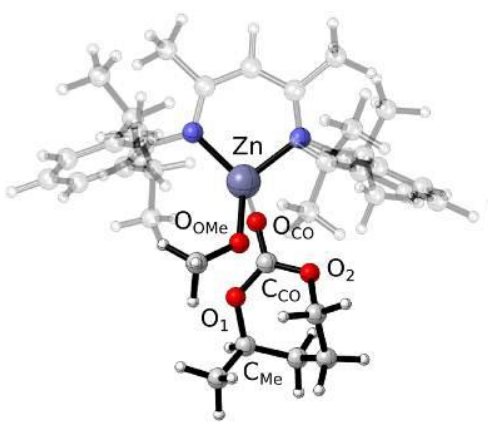

a) $I_{7 C C-y(R, r e)}$

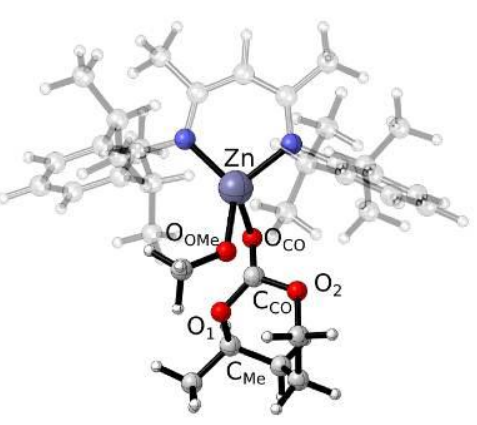

b) $T S_{\mathrm{l}_{7 C C-\gamma(R, r e)} \rightarrow I_{7 C C-\gamma(R, r e)}^{5 \alpha}}$

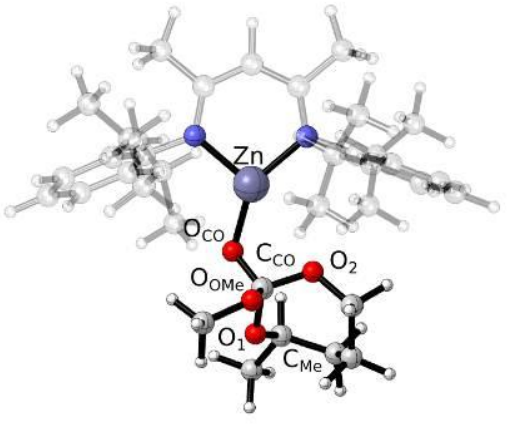

C) $I_{7 C C-\gamma(R, r e)}^{\delta \alpha}$

Figure 6. Optimized structures of the complexes involved in the nucleophilic attack step of the ROP of $7 \mathrm{CC}-\gamma(R, r e)$ mediated by $\left[\left(\mathrm{BDI}^{\mathrm{iPr}}\right) \mathrm{Zn}(\mathrm{OMe})\right]$. In order to differentiate the two alkoxy oxygen atoms of the carbonate ester functional group, the oxygen atom closest to the substituted carbon atom is labelled $\mathrm{O}_{1}$; the other oxygen atom is then labelled $\mathrm{O}_{2}$.

This transition state leads to the adduct $\mathbf{I I}^{\alpha \delta_{7 C C}-\gamma(R, r e)}$ (Figure $7 \mathrm{f}$ ), calculated to be endergonic by $+14.4 \mathrm{kcal} . \mathrm{mol}^{-1}$ with respect to the entrance channel $\left(+8.6 \mathrm{kcal} . \mathrm{mol}^{-1}\right.$ with respect to $\left.\mathbf{I I}^{\delta \alpha}{ }_{7 \mathrm{CC}-\gamma(R, r e)}\right)$. For this intermediate, the $\mathrm{Zn}-\mathrm{O}_{2}$ distance is elongated whereas the $\mathrm{Zn}-\mathrm{O}_{1}$ is shortened in good agreement with the tilting motion. The formation of a $\mathrm{Zn}-\mathrm{O}_{1}$ interaction induces an increase of the steric repulsion between the methyl groups of the 7CC$\gamma(R, r e)$ (in $\alpha$ position of $\mathrm{O}_{1}$ and of the methoxy moiety) and the $\beta$-diketiminate ligand, which explains the stability difference between $\mathbf{I I}^{\delta \alpha}{ }_{7 \mathrm{CC}-\gamma(R, r e)}$ and $\mathbf{I I}^{\alpha{ }^{\alpha}}{ }_{7 \mathrm{CC}-\gamma(R, r e)}$ as well as the elongation of the $\mathrm{Zn}-\mathrm{O}_{\mathrm{CO}}$ distance. Subsequently from $\mathbf{I I}^{\alpha \delta}{ }_{7 \mathrm{CC}-\gamma(R, r e)}$, as for $\mathbf{I I}^{\delta \alpha}{ }_{7 \mathrm{CC}-\gamma(R, r e)}$, the ring-opening step takes place through an accessible transition state $\operatorname{TS}\left(\mathbf{I I}^{\alpha \delta}{ }_{7 \mathrm{CC}-\gamma(R, r e)} \rightarrow \mathbf{I I I}^{\alpha \delta_{7 \mathrm{CC}}}\right.$ $\gamma(R, r e)$ ) (Figure $7 \mathrm{~g}$ ), which lies $+15.7 \mathrm{kcal}^{\mathrm{m} m o l}{ }^{-1}$ above the entrance channel and $+1.3 \mathrm{kcal}^{\mathrm{mol}} \mathrm{mol}^{-1}$

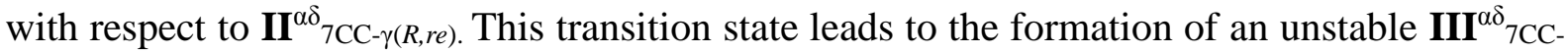
$\gamma(R, r e)$ intermediate (Figure $7 \mathrm{~h}$ ) located at $+6.5 \mathrm{kcal}^{\mathrm{mol}}{ }^{-1}$ with respect to the separated reactants. From geometrical considerations, for $\operatorname{TS}\left(\mathbf{I I}^{\alpha \delta_{7 C C}-\gamma(R, r e)} \rightarrow \mathbf{I I I}^{\alpha \delta_{7 C C}-\gamma(R, r e)}\right)$, the endocyclic oxygen $\mathrm{O}_{1}$ interacts with the metal centre whereas the exocyclic oxygen $\mathrm{O}_{\mathrm{CO}}$ moves away. These coordination changes lead to the partially opened $7 \mathrm{CC}-\gamma(R, r e)$ ring, as 
shown by the increase of the $\mathrm{C}_{\mathrm{CO}}-\mathrm{O}_{1}$ distance. At the stage of $\mathbf{I I I}^{\alpha \delta_{7 \mathrm{CC}} \gamma(R, r e)}$, the $7 \mathrm{CC}-\gamma(R, r e)$ is fully open. As for III $^{\delta \alpha}{ }_{7 \mathrm{CC}-\gamma(R, r e)}$, the hybridization of the $\mathrm{C}_{\mathrm{CO}}$ carbon changes from $\mathrm{sp}^{3}$ to $\mathrm{sp}^{2}$, as indicated by its planarity (sum of angles around $\mathrm{C}_{\mathrm{CO}}=360^{\circ}$ ). The $\mathrm{C}_{\mathrm{CO}}-\mathrm{O}_{\mathrm{CO}}$ distance is shortened, thus supporting the relocalization of a double bond between these two atoms. Finally, the same decoordination process occurs via an accessible transition state TS(III ${ }^{\alpha \delta}{ }_{7 \mathrm{CC}-}$

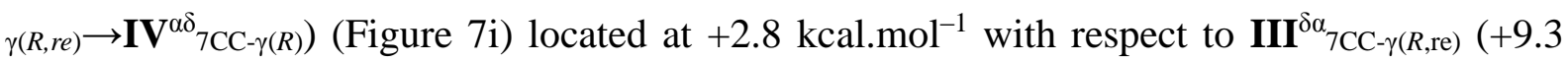
$\mathrm{kcal}^{\mathrm{mol}} \mathrm{l}^{-1}$ with respect to the entrance channel). The formation of the final product $\mathbf{I} \mathbf{V}^{\alpha \delta_{7 C C}-\gamma(R)}$ is a slightly exergonic process, as for $\mathbf{I V}^{\delta \alpha} \alpha_{7 \mathrm{CC}-\gamma(R)}$. Thus, the two considered pathways leading to a growing polymer chain carrying a methyl group in $\delta \alpha$ or $\alpha \delta$ position are competitive from a thermodynamic and kinetic point of view. 


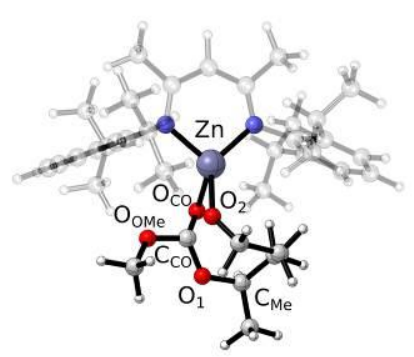

a) $T S_{\| I_{7 C C-\gamma(R, r e)}^{5 \alpha} \rightarrow 1 I_{7 C C-\gamma(R, r e)}^{5 \alpha}}$

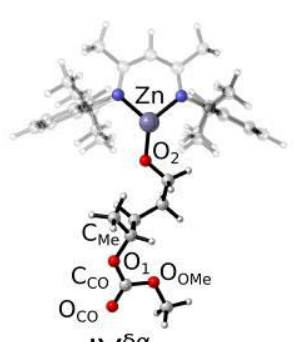

d) $I V_{7 C C-Y(R)}^{\delta \alpha}$

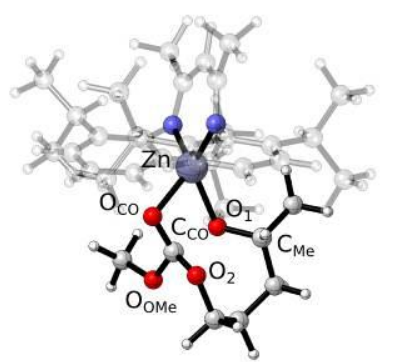

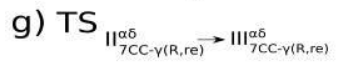

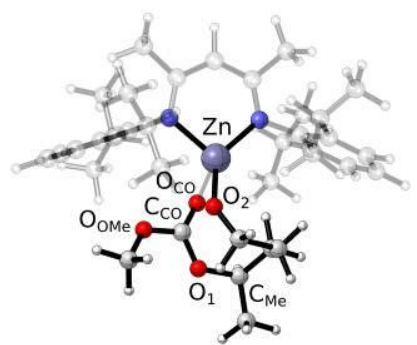

b) $11{ }_{7 C C-\gamma(R, r e)}^{\delta \alpha}$

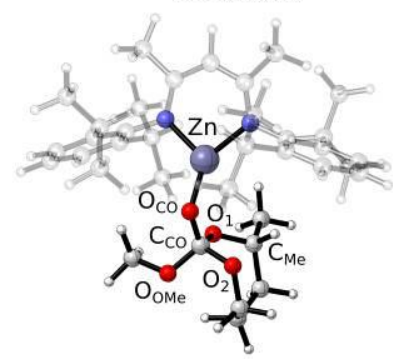

e) $T S_{\|\|_{7 C-\gamma(R, r e)}^{5 \alpha} \rightarrow \|_{7 C C-\gamma(R, r e)}^{\alpha \delta}}$

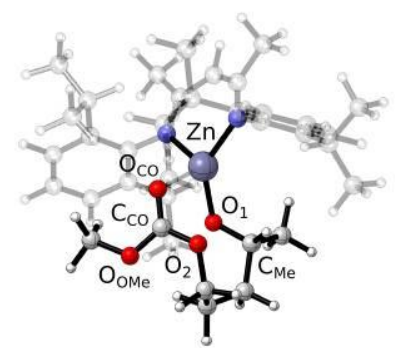

h) ${ }_{1 I}^{\alpha \delta}{ }_{7 C C-\gamma(R, r e)}$

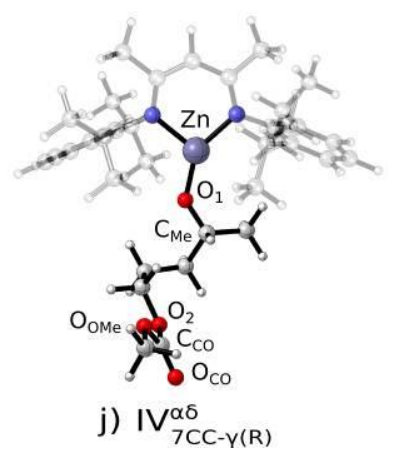

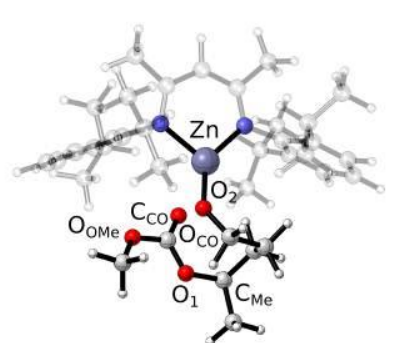

C) $T S_{\| I_{7 C(-\gamma(R, r e)}^{\delta \alpha} \rightarrow I V_{7 C C-\gamma(R)}^{5 \alpha}}$

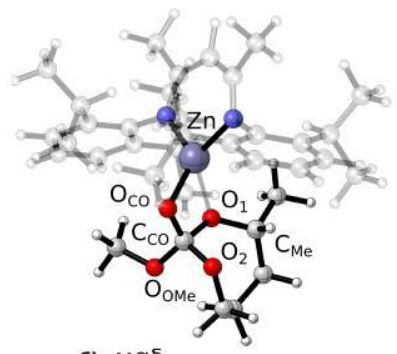

f) $I_{7 C C-\gamma(R, r e)}^{\alpha \delta}$

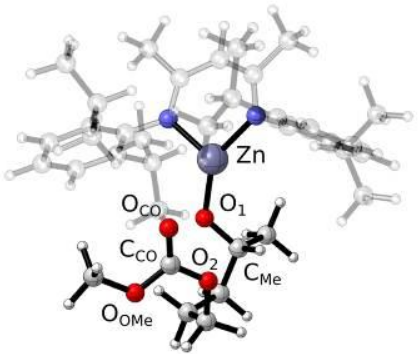

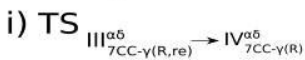

Figure 7. Optimized structures of complexes involved in the initiation step of the ROP of 7CC- $\gamma(R)$ mediated by [(BDI $\left.\left.{ }^{\mathrm{iPr}}\right) \mathrm{Zn}(\mathrm{OMe})\right]$.

The Gibbs-free energy profile determined for the initiation reaction of the 7CC- $\gamma(R, s i)$ polymerization mediated by $\left[\left(\mathrm{BDI}^{\mathrm{iPr}}\right) \mathrm{Zn}(\mathrm{OMe})\right]$, in which the nucleophilic attack takes place on the si enantioface, is presented in Figure 8. 


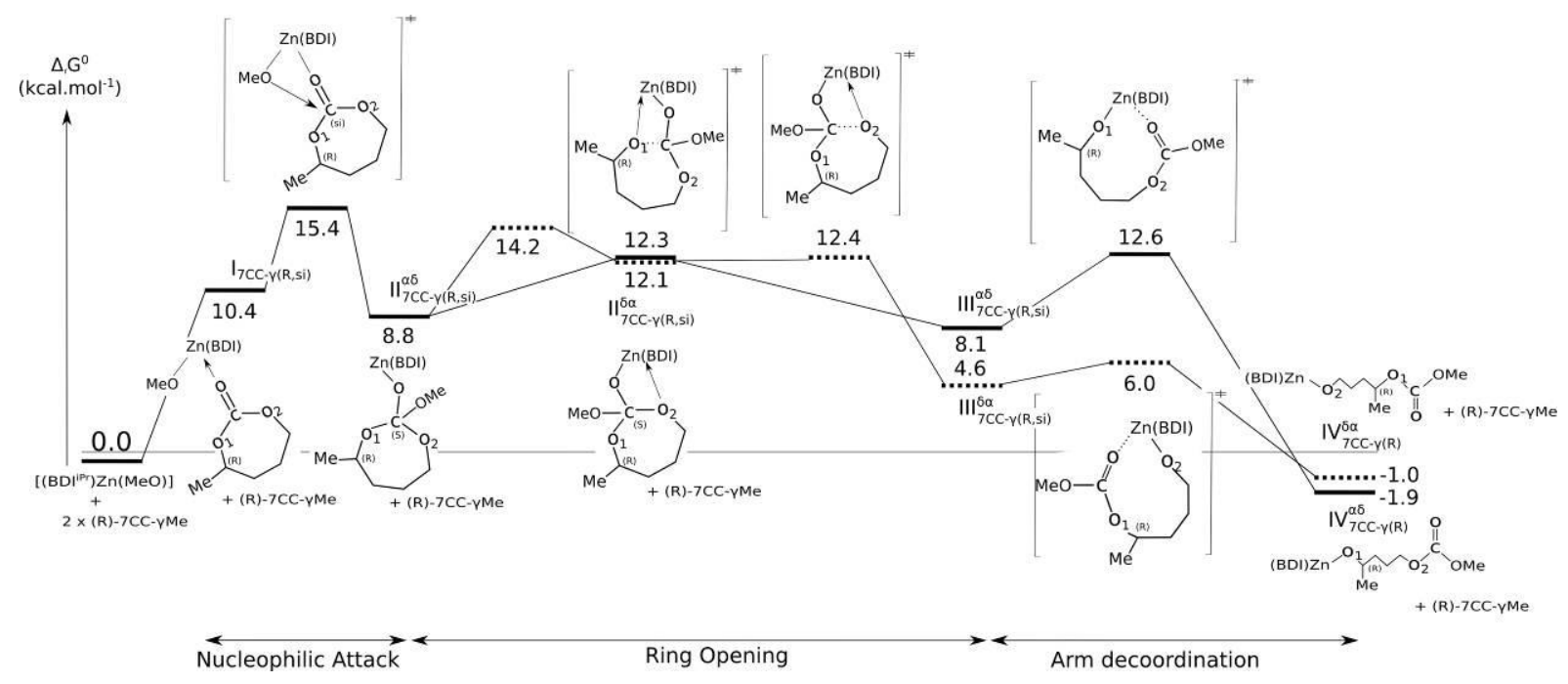

Figure 8. Calculated free-energy profile of the initiation step of the ROP of $7 \mathrm{CC}-\gamma(R, s i)$ mediated by $\left[\left(\mathrm{BDI}^{\mathrm{iPr}}\right) \mathrm{Zn}(\mathrm{OMe})\right]$.

It is noteworthy that the initiation reaction mediated by the nucleophilic attack on this si enantioface eventually leads to the same two products obtained by the nucleophilic attack on the re enantioface, i.e., $\mathbf{I} \mathbf{V}^{\alpha \delta_{7 \mathrm{CC}-\gamma(R)}}$ and $\mathbf{I} \mathbf{V}^{\delta \alpha}{ }_{7 \mathrm{CC}-\gamma(R)}$. The overall energy data and the geometrical parameters (Table S1) for this initiation step are similar to those obtained starting by the nucleophilic attack on the re enantioface. The reaction begins with the formation of an endergonic $\mathbf{I}_{7 \mathrm{CC}-\gamma(R, s i)}$ adduct (Figure 9a), with a Gibbs-free energy of $10.4 \mathrm{kcal} \mathrm{mol}^{-1}$ with respect to the separated reactants. For $\mathbf{I}_{7 \mathrm{CC}-\gamma(R, s i)}$ (as for $\mathbf{I}_{7 \mathrm{CC}-\gamma(R, r e)}$ ), the carbonate monomer is coordinated to the zinc atom by its exocyclic oxygen atom. The nucleophilic attack of the oxygen atom of the methoxy moiety onto the carbonyl carbon of $7 \mathrm{CC}-\gamma(R, s i)$ proceeds through an accessible transition state $\operatorname{TS}\left(\mathbf{I}_{7 \mathrm{CC}-\gamma(R, s i)} \rightarrow \mathbf{I I}^{\alpha \delta_{7 C C}-\gamma(R, s i)}\right)$ located at $+15.4 \mathrm{kcal} \mathrm{mol}^{-1}$ with respect to the entrance channel $\left(+5.0 \mathrm{kcal}^{\mathrm{mol}}{ }^{-1}\right.$ with respect to $\left.\mathbf{I}_{7 \mathrm{CC}-\gamma(R, s i)}\right)$. The corresponding activation barrier $\left(+5.0 \mathrm{kcal} . \mathrm{mol}^{-1}\right.$ with respect to $\mathbf{I}_{7 \mathrm{CC}-\gamma(R, s i)}$ adduct) is close to that computed for the nucleophilic attack on the re enantionface $\left(+4.1 \mathrm{kcal}^{\mathrm{mol}} \mathrm{m}^{-1}\right.$ above the

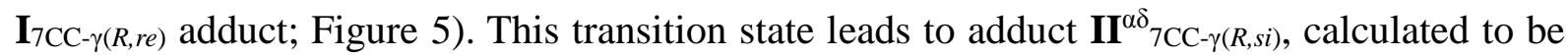
endergonic by $+8.8 \mathrm{kcal}_{\mathrm{mol}}^{-1}$ with respect to the separated reactants. In this case, and conversely to the nucleophilic attack on the re enantioface, the nucleophilic attack leads to an 14 
$\alpha \delta$ adduct and not to an $\delta \alpha$ adduct. The formation of $\mathbf{I I}^{\delta \alpha} 7 \mathrm{CC}-\gamma(R, s i)$ is endoergic by +3.3 kcal.mol ${ }^{-1}$ with respect to $\mathbf{I I}^{\alpha \delta_{7 C C}-\gamma(R, s i)}$. The formation of this adduct takes place via an accessible transition state $\operatorname{TS}\left(\mathbf{I I}^{\alpha \delta_{7 C C}-\gamma(R, s i)} \rightarrow \mathbf{I I}^{\delta \alpha}{ }_{7 \mathrm{CC}-\gamma(R, s i)}\right)$ located at $+5.4 \mathrm{kcal} . \mathrm{mol}^{-1}$ with respect to $\mathbf{I I}^{\alpha \delta_{7 C C}-\gamma(R, s i)}$. At $\mathbf{I I}^{\delta \alpha}{ }_{7 \mathrm{CC}-\gamma(R, s i)}$, the formation of a $\mathrm{Zn}-\mathrm{O}_{2}$ interaction leads to the partially opened 7CC- $\gamma(R, s i)$ cycle, as evidenced by the increase of the $\mathrm{C}_{\mathrm{CO}}-\mathrm{O}_{2}$ distance from $1.402 \AA$ for $\mathbf{I I}^{\alpha \delta}{ }_{7 \mathrm{CC}-\gamma(R, s i)}$ to $1.568 \AA$ for $\mathbf{I I}^{\delta \alpha} 7 \mathrm{CC}-\gamma(R, s i)$, which explains the stability difference between both adducts.

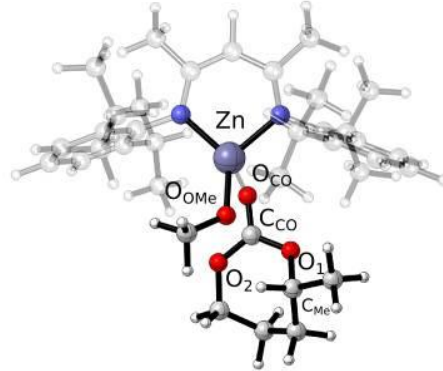

a) $I_{7 C C-\gamma(R, s i)}$

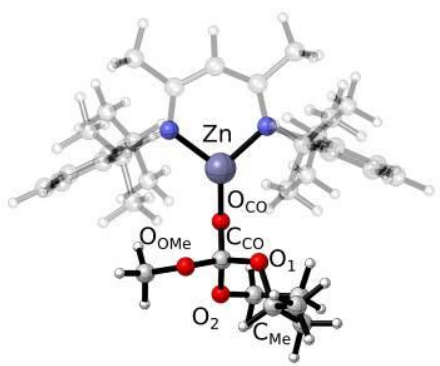

b) $I_{7 C C-\gamma(R, s i)}^{\alpha \delta}$

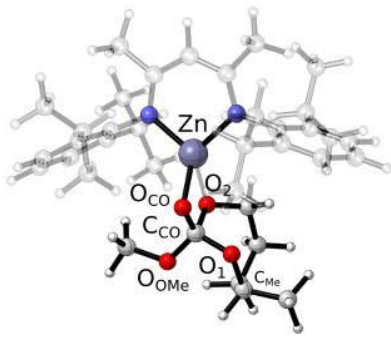

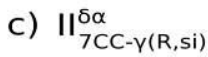

Figure 9. Optimized structures of $\mathrm{I}_{7 \mathrm{CC}-\gamma(R, s i)}, \mathrm{II}^{\alpha \delta_{7 \mathrm{CC}-\gamma(R, s i)}}$ and $\mathrm{II}^{\delta \alpha}{ }_{7 \mathrm{CC}-\gamma(R, s i)}$.

From $\mathbf{I I}^{\alpha \delta_{7 C C}-\gamma(R, s i)}$ and $\mathbf{I I}^{\delta \alpha}{ }_{7 \mathrm{CC}-\gamma(R, s i)}$, the reaction continues via either $\mathrm{TS}\left(\mathbf{I I}^{\alpha \delta_{7 C C}}\right.$ $\left.\gamma(R, s i) \rightarrow \mathbf{I I I}^{\alpha \delta}{ }_{7 \mathrm{CC}-\gamma(R, s i)}\right)$ or $\mathrm{TS}\left(\mathbf{I I}^{\delta \alpha}{ }_{7 \mathrm{CC}-\gamma(R, s i)} \rightarrow \mathbf{I I I}^{\delta \alpha}{ }_{7 \mathrm{CC}-\gamma(R, s i)}\right)$, respectively, that corresponds to the acyl-oxygen bond cleavage of the 7CC- $\gamma(R, s i)$ cycle, with similar activation barriers, around +12.2 kcal.mol ${ }^{-1}$ with respect to the separated reactants. These transition states lead to the formation of two endergonic intermediates $\mathbf{I I I}^{\alpha \delta}{ }_{7 \mathrm{CC}-\gamma(R, s i)}$ and $\mathbf{I I I}{ }^{\delta \alpha}{ }_{7 \mathrm{CC}-\gamma(R, s i)}$, respectively, by

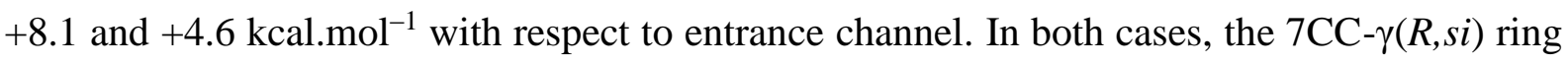

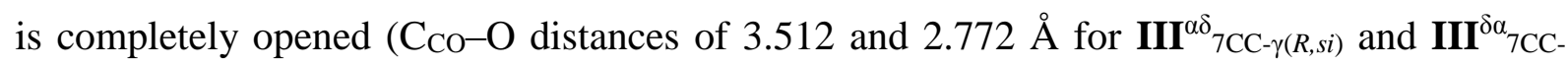
$\gamma(R, s i)$, respectively) and the intracyclic oxygen atom, $\mathrm{O}_{1}$ for $\mathbf{I I}^{\alpha \delta_{7 \mathrm{CC}-\gamma(R, s i)}}$ and $\mathrm{O}_{2}$ for $\mathbf{I I}^{\delta \alpha}{ }_{7 \mathrm{CC}-\gamma(R, s i)}$, ensures the coordination to the metal center $\left(\mathrm{Zn}-\mathrm{O}_{\text {intra }}\right.$ distances of 1.875 and

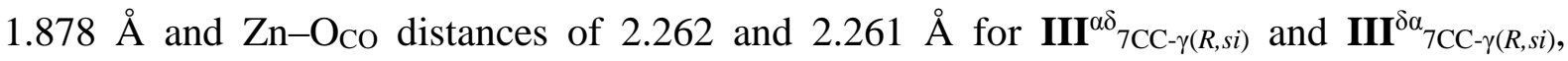
respectively). The last step concerns the relaxation of the growing polymer chain that essentially consists in the decoordination of the carbonate arm yielding to $\mathbf{I V}^{\alpha \delta_{7 C C}-\gamma(R)}$ and 
$\mathbf{I V}^{\delta \alpha^{7 C C}-\gamma(R)}$. The activation energy for this reaction is calculated to be +12.6 and +6.0 kcal.mol ${ }^{-1}$ above the entrance channel for $\operatorname{TS}\left(\mathbf{I I I}^{\alpha \delta_{7 C C}-\gamma(R, s i)} \rightarrow \mathbf{I V}^{\alpha \delta_{7 C C}-\gamma(R)}\right)$ and $\mathrm{TS}\left(\mathbf{I I I}^{\delta \alpha}{ }_{7 \mathrm{CC}-}\right.$ $\left.\gamma(R, s i) \rightarrow \mathbf{I} \mathbf{V}^{\delta \alpha_{7 C-} \gamma(R)}\right)$, respectively. As for the nucleophilic attack on the re enantioface, the computed low barriers are in line with a kinetically readily accessible and exergonic process. Thus, the formation of the final products $\mathbf{I} \mathbf{V}^{\alpha \delta^{\delta}} 7 \mathrm{CC}-\gamma(R)$ and $\mathbf{I V}{ }^{\delta \alpha} 7 \mathrm{CC}-\gamma(R)$ can take place through two plausible pathways with or without a tilting motion step. From the kinetic point of view, the formation of the two products is found to be exergonic with similar activation barriers. However, the calculations suggest that the rate-determining step is the nucleophilic attack, indicating that the tilting step would not play a crucial role on the formation of the final products. On the basis of this theoretical finding, we have not considered the reaction pathways involving the tilting motion for the study of the nucleophilic attack of the carbonate ester arm (i.e., first growing polymer chain) of $\mathbf{I V}^{\alpha \delta_{7 \mathrm{CC}-\gamma(R)}}$ and $\mathbf{I V}^{\delta \alpha}{ }_{7 \mathrm{CC}-\gamma(R)}$ on both enantiofaces of a second 7CC- $\gamma(R)$.

Table 1. Comparison of the relative Gibbs-free energies $\left(\mathrm{kcal}^{\mathrm{m}} \mathrm{mol}^{-1}\right)$ of the intermediates and transition states in the initiation reaction of the ROP of 7CC- $\gamma(R, r e), 7 \mathrm{CC}-\gamma(R, s i), 7 \mathrm{CC}-\gamma(S, r e)$ and 7CC- $\gamma(S$,si). The labels I to IV refer to the intermediates and transition states shown in Figures 5 and 8.

\begin{tabular}{|c|c|c|c|c|c|}
\hline Monomer & $7 \mathrm{CC}-\gamma(R)$ & $7 \mathrm{CC}-\gamma(S)$ & & $7 \mathrm{CC}-\gamma(R)$ & $7 \mathrm{CC}-\gamma(S)$ \\
\hline Considered Enantioface & re & re & & $s i$ & si \\
\hline \multicolumn{6}{|c|}{ Nucleophilic attack } \\
\hline $\mathbf{I}_{7 \mathrm{CC}}$ & 11.8 & 13.4 & $\mathbf{I}_{7 \mathrm{CC}}$ & 10.4 & 13.0 \\
\hline $\mathrm{TS}\left(\mathbf{I}_{7 \mathrm{CC}} \rightarrow \mathbf{I I}^{\delta \alpha}{ }_{7 \mathrm{CC}}\right)$ & 15.9 & 18.1 & $\mathrm{TS}\left(\mathbf{I}_{7 \mathrm{CC}} \rightarrow \mathbf{I I}^{\alpha}{ }_{7 \mathrm{CC}}\right)$ & 15.4 & 20.5 \\
\hline $\mathbf{I I}^{\delta \alpha_{7 C C}}$ & 5.8 & 9.9 & $\mathbf{I I}^{\alpha \delta_{7 \mathrm{CC}}}$ & 8.8 & 7.6 \\
\hline
\end{tabular}




\begin{tabular}{|c|c|c|c|c|c|}
\hline $\mathrm{TS}\left(\mathbf{I I}^{\delta \alpha}{ }_{7 \mathrm{CC}} \rightarrow \mathbf{I I I}^{\delta \alpha}{ }_{7 \mathrm{CC}}\right)$ & 14.3 & 16.7 & $\mathrm{TS}\left(\mathbf{I I}^{\alpha \delta_{7 \mathrm{CC}}} \rightarrow \mathbf{I I I}^{\alpha \delta_{7 \mathrm{CC}}}\right)$ & 12.3 & 17.7 \\
\hline III $^{\delta \alpha} 7 \mathrm{CC}$ & 10.3 & 12.6 & $\mathbf{I I I}^{\alpha \delta_{7 \mathrm{CC}}}$ & 8.1 & 9.3 \\
\hline $\mathrm{TS}\left(\mathbf{I I}^{\delta \alpha}{ }_{7 \mathrm{CC}} \rightarrow \mathbf{I I}^{\alpha \delta_{7 \mathrm{CC}}}\right)$ & 16.2 & 21.3 & $\mathrm{TS}\left(\mathbf{I I}^{\alpha \delta_{7 \mathrm{CC}}} \rightarrow \mathbf{I I}^{\delta \alpha}{ }_{7 \mathrm{CC}}\right)$ & 14.2 & 15.9 \\
\hline $\mathbf{I I}^{\alpha \delta_{7 C C}}$ & 14.4 & 13.2 & $\mathbf{I I}^{\delta \alpha}{ }_{7 \mathrm{CC}}$ & 12.1 & 13.7 \\
\hline $\mathrm{TS}\left(\mathbf{I I}^{\alpha \delta_{7 \mathrm{CC}}} \rightarrow \mathbf{I I I}^{\alpha \delta_{7 \mathrm{CC}}}\right)$ & 15.7 & 23.4 & $\mathrm{TS}\left(\mathbf{I I}^{\delta \alpha}{ }_{7 \mathrm{CC}} \rightarrow \mathbf{I I I}^{\delta \alpha}{ }_{7 \mathrm{CC}}\right)$ & 12.4 & 14.6 \\
\hline IIII $^{\alpha \delta}{ }_{7 \mathrm{CC}}$ & 6.5 & 12.1 & III $^{\delta \alpha}{ }_{7 \mathrm{CC}}$ & 4.6 & 7.5 \\
\hline \multicolumn{6}{|c|}{ Arm decoordination - chain relaxation } \\
\hline $\mathrm{TS}\left(\mathbf{I I I}^{\delta \alpha}{ }_{7 \mathrm{CC}} \rightarrow \mathbf{I V}^{\delta \alpha}{ }_{7 \mathrm{CC}}\right)$ & 10.7 & 12.8 & $\mathrm{TS}\left(\mathbf{I I I}{ }^{\alpha \delta}{ }_{7 \mathrm{CC}} \rightarrow \mathbf{I V}^{\alpha \delta_{7 \mathrm{CC}}}\right)$ & 12.6 & 10.8 \\
\hline $\mathbf{I} \mathbf{V}^{\delta \alpha} 7 \mathrm{CC}$ & -1.0 & 1.6 & $\mathbf{I V}^{\alpha \delta_{7 \mathrm{CC}}}$ & -1.9 & -1.7 \\
\hline $\operatorname{TS}\left(\mathbf{I I I}^{\alpha \delta_{7 \mathrm{CC}}} \rightarrow \mathbf{I V}^{\alpha \delta_{7 \mathrm{CC}}}\right)$ & 9.3 & 13.6 & $\mathrm{TS}\left(\mathbf{I I I}{ }^{\delta \alpha}{ }_{7 \mathrm{CC}} \rightarrow \mathbf{I V}^{\delta \alpha_{7 \mathrm{CC}}}\right)$ & 6.0 & 9.7 \\
\hline $\mathbf{I V}^{\alpha \delta_{7 \mathrm{CC}}}$ & -1.9 & -1.7 & $\mathbf{I V}^{\delta \alpha}{ }_{7 \mathrm{CC}}$ & -1.0 & 1.6 \\
\hline
\end{tabular}

The relative Gibbs-free energies of the intermediates and the activation barriers involved in the initiation reaction of $7 \mathrm{CC}-\gamma(R)$ and $7 \mathrm{CC}-\gamma(S)$ ROP are also very close (Table 1). In all cases, the formation of the final $\alpha \delta$ and $\delta \alpha$ products is predicted thermodynamically exergonic and kinetically accessible. For the sake of clarity, due to the similarity between the relative Gibbs-free energies of the intermediates and the activation barriers of the ROP of 7CC- $\gamma(R)$ and 7CC- $\gamma(S)$, the following discussion about the insertion of a second 7CC- $\gamma(R)$ moiety has been limited to $\mathbf{I} \mathbf{V}^{\alpha \delta_{7 C C}-\gamma(R)}$ and $\mathbf{I} \mathbf{V}^{\delta \alpha}{ }_{7 \mathrm{CC}-\gamma(R)}$. 


\section{Propagation step of the ROP of 7CC- $\gamma \mathrm{Me}$.}

The second carbonate insertion, corresponding to the first propagation step, has been computed in order to get a deeper insight into the ROP of $\gamma$-substituted tetramethylene carbonates $(7 \mathrm{CC}-\gamma(R))$. The energy profile computed for the first propagation step is depicted in Figure 10. In each case, the Gibbs-free energies for intermediates and transitions states $\left(\mathrm{kcal}_{\mathrm{mol}}{ }^{-1}\right)$ are relative to the total Gibbs-free energies of reactants (i.e., [(BDI $\left.{ }^{\mathrm{iPr}}\right) \mathrm{Zn}(\mathrm{OMe})$ ] $+27 \mathrm{CC}-\gamma(R))$. The optimized structures of the relevant stationary points of the potential energy surface and pertinent bond lengths are shown in Figures 11, S1 and S2.

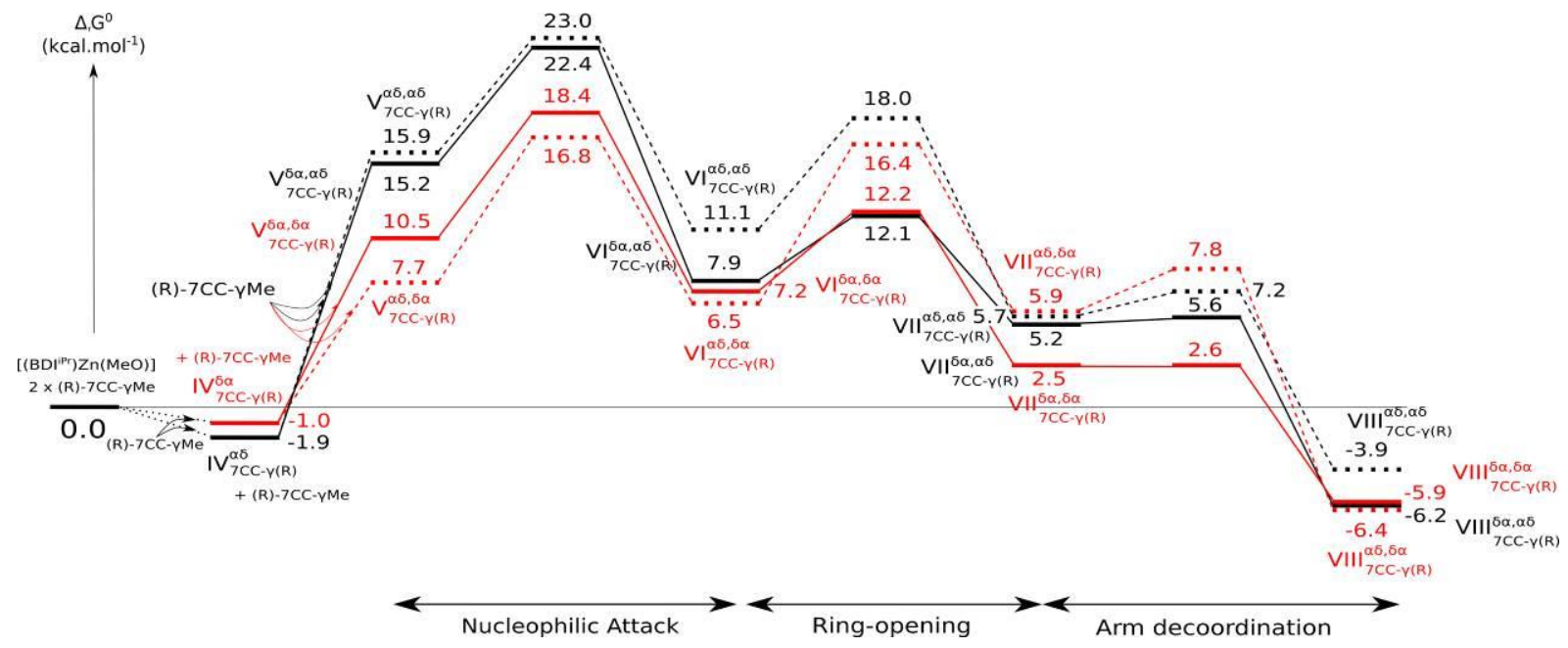

Figure 10. Calculated Gibbs-free energy profile of the propagation step of the ROP of 7CC$\gamma(R)$ mediated by $\left[\left(\mathrm{BDI}^{\mathrm{iPr}}\right) \mathrm{Zn}(\mathrm{OMe})\right]$. Black lines correspond to the propagation step mediated by $\mathbf{I}{ }^{\alpha \delta_{7 C C}-\gamma(R)}$; Red lines to the propagation step mediated by $\mathbf{I V}^{\delta \alpha}{ }_{7 \mathrm{CC}-\gamma(R)}$; Solid lines leading to a final $\delta \alpha$ product; Dashed lines leading to a final $\alpha \delta$ product.

The reaction mechanism for this second step is similar to the one of the initiation step. For each of the two products $\mathbf{I} \mathbf{V}^{\alpha \delta_{7 \mathrm{CC}-\gamma(R)}}$ and $\mathbf{I} \mathbf{V}^{\delta \alpha}{ }_{7 \mathrm{CC}-\gamma(R)}$, two pathways have been explored, leading to a growing polymer chain carrying a methyl group at the $\delta$ position with respect to 
the oxygen atom coordinated to the metal centre and therefore in $\alpha$ position of the oxygen atom of the carbonate ester group (VIII ${ }^{\delta \alpha, \delta \alpha}{ }_{7 \mathrm{CC}-\gamma(R)}$ Figure 11a and VIIII ${ }^{\delta \alpha, \alpha \delta_{7 C C}-\gamma(R)}$ Figure 11b), or in $\alpha$ and $\delta$ position with respect to the same group of oxygen atoms (VIII ${ }^{\alpha \delta, \delta \alpha}{ }_{7 C C-\gamma(R)}$ Figure $11 \mathrm{c}$ and VIII ${ }^{\alpha \delta, \alpha \delta_{7 C C}-\gamma(R)}$ Figure 11d). The coordination of a second $7 \mathrm{CC}-\gamma(R)$ onto $\mathbf{I V}^{\alpha \delta_{7 \mathrm{CC}-\gamma(R)}}$ and $\mathbf{I V}^{\delta \alpha}{ }_{7 \mathrm{CC}-\gamma(R)}$ proceeds through the coordination of $7 \mathrm{CC}-\gamma(R)$ to the zinc centre by its exocyclic oxygen atom. These coordination modes are predicted to be endergonic between +7.7 and +10.5 kcal.mol ${ }^{-1}$ for adducts to $\mathbf{I V}^{\delta \alpha}{ }_{7 \mathrm{CC}-\gamma(R)}\left(\mathbf{V}^{\alpha \delta, \delta \alpha_{7 \mathrm{CC}-\gamma(R)}}\right.$ and $\mathbf{V}^{\delta \alpha, \delta \alpha}{ }_{7 \mathrm{CC}-\gamma(R)}$,

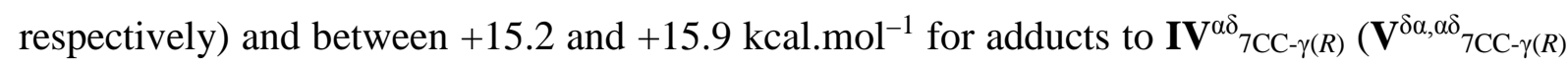
and $\mathbf{V}^{\alpha \delta, \alpha \delta_{7 C C}-\gamma(R)}$, respectively), with respect to the entrance channel. This difference can easily be explained considering the lower steric hindrance around the metal centre imposed by

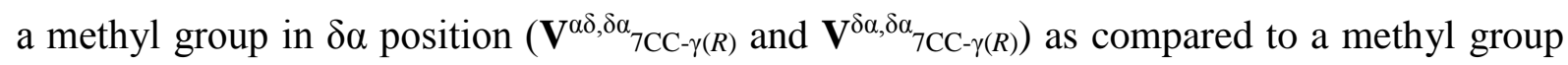
in $\alpha \delta$ position $\left(\mathbf{V}^{\delta \alpha, \alpha \delta_{7 C C}-\gamma(R)}\right.$ and $\left.\mathbf{V}^{\alpha \delta, \alpha \delta_{7 C C}-\gamma(R)}\right)$. The reaction then proceeds through the nucleophilic attack of the oxygen atom of the growing alkoxide chain onto the carbonyl carbon $\left(\mathrm{C}_{\mathrm{CO}}\right)$ of the coordinated $7 \mathrm{CC}-\gamma \mathrm{R}$ monomer, through either $\mathrm{TS}\left(\mathbf{V}^{\alpha \delta, \delta \alpha}{ }_{7 \mathrm{CC}-}\right.$

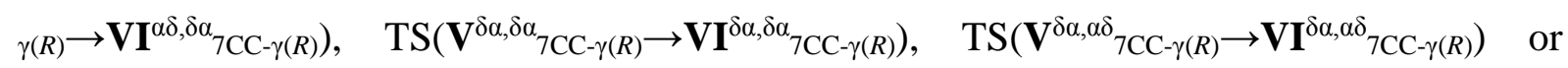
$\mathrm{TS}\left(\mathbf{V}^{\alpha \delta, \alpha \delta}{ }_{7 \mathrm{CC}-\gamma(R)} \rightarrow \mathbf{V I}^{\alpha \delta, \alpha \delta}{ }_{7 \mathrm{CC}-\gamma(R)}\right)$. From a kinetic point of view, the activation barriers for this process are close in energy ranging from 7.1 to $9.1 \mathrm{kcal}^{\mathrm{mol}}{ }^{-1}$ with respect to the corresponding adducts, and from 16.8 to $23.0 \mathrm{kcal} . \mathrm{mol}^{-1}$ with respect to the entrance channel. Similar geometrical features are observed in all four cases going from the adduct to the fourmembered metallacycle transition state. In particular, the pyramidalisation of the 7CC- $\gamma(R)$ carbonyl carbon in order for the empty $\mathrm{sp}^{3}$ orbital to point towards the oxygen atom $\left(\mathrm{O}_{1}\right.$ or $\mathrm{O}_{2}$ ) of the alkoxide growing chain, as well as the decrease of the $\mathrm{Zn}-\mathrm{O}_{\mathrm{CO}}$ distance by around $0.15 \AA$ with the concomitant elongation of the $\mathrm{O}_{\mathrm{CO}}-\mathrm{C}_{\mathrm{CO}}$ and $\mathrm{Zn}-\mathrm{O}_{1}$ or $\mathrm{Zn}-\mathrm{O}_{2}$ bond lengths by 0.02 and $0.1 \AA$, respectively, are relevant. The formation of the resulting intermediates, $\mathbf{V I} \mathbf{I}^{\alpha \delta, \delta \alpha_{7 C C}-\gamma(R)}, \quad \mathbf{V} \mathbf{I}^{\delta \alpha, \delta \alpha}{ }_{7 \mathrm{CC}-\gamma(R)}, \quad \mathbf{V I} \mathbf{I}^{\delta \alpha, \alpha \delta_{7 C C}-\gamma(R)}$ and $\mathbf{V I} \mathbf{I}^{\alpha \delta, \alpha \delta_{7 C C}-\gamma(R)}$, as for the initiation step, are predicted to be exergonic with respect to the previous adducts, but remains endergonic with 
respect to the separated reactants, between +6.5 and $+11.1 \mathrm{kcal}^{\mathrm{mol}}{ }^{-1}$. From these intermediates, the ring-opening of the seven-membered heterocyclic rings takes place, leading to the formation of $\mathbf{V I I}{ }^{\alpha \delta, \delta \alpha_{7 C C}-\gamma(R)}, \mathbf{V I I}{ }^{\delta \alpha, \delta \alpha_{7 C C}-\gamma(R)}, \mathbf{V I I}^{\delta \alpha, \alpha \delta_{7 C C}-\gamma(R)}$ and $\mathbf{V I I}{ }^{\alpha \delta, \alpha \delta_{7 C C}-\gamma(R)}$ through the corresponding transition states $\quad \mathrm{TS}\left(\mathbf{V I}^{\alpha \delta, \delta \alpha}{ }_{7 \mathrm{CC}-\gamma(R)} \rightarrow \mathbf{V I I}{ }^{\alpha \delta, \delta \alpha}{ }_{7 \mathrm{CC}-\gamma(R)}\right), \quad \mathrm{TS}\left(\mathbf{V I}^{\delta \alpha, \delta \alpha}{ }_{7 \mathrm{CC}-}\right.$ $\left.\gamma(R) \rightarrow \mathbf{V I I}{ }^{\delta \alpha, \delta \alpha}{ }_{7 \mathrm{CC}-\gamma(R)}\right), \quad \operatorname{TS}\left(\mathbf{V I}^{\delta \alpha, \alpha \delta_{7 \mathrm{CC}-\gamma(R)}} \rightarrow \mathbf{V I I}{ }^{\delta \alpha, \alpha \delta_{7 C C}-\gamma(R)}\right)$ and $\operatorname{TS}\left(\mathbf{V I}^{\alpha \delta, \alpha \delta}{ }_{7 \mathrm{CC}-\gamma(R)} \rightarrow \mathbf{V I I}{ }^{\alpha \delta, \alpha \delta}{ }_{7 \mathrm{CC}-}\right.$ $\gamma(R))$. The activation barriers for this step are $18.0 \mathrm{kcal}^{\mathrm{mol}} \mathrm{mol}^{-1}\left(\mathrm{TS}\left(\mathbf{V I}^{\alpha \delta, \alpha \delta}{ }_{7 \mathrm{CC}-\gamma(R)} \rightarrow \mathbf{V I I}^{\alpha \delta, \alpha \delta}{ }_{7 \mathrm{CC}-}\right.\right.$ $\gamma(R)))$ and $16.4 \mathrm{kcal}^{\mathrm{mol}}{ }^{-1}\left(\mathrm{TS}\left(\mathbf{V I} \mathbf{I}^{\alpha \delta, \delta \alpha}{ }_{7 \mathrm{CC}-\gamma(R)} \rightarrow \mathbf{V I I}{ }^{\alpha \delta, \delta \alpha}{ }_{7 \mathrm{CC}-\gamma(R))}\right)\right.$ when the cleavage of the acyl-oxygen bond takes place on the most hindered oxygen-acyl $\mathrm{O}_{1}{ }_{1}-\mathrm{C}(\mathrm{O})(\mathrm{O})$ bond compared with $12.2 \mathrm{kcal} \mathrm{mol}^{-1}\left(\mathrm{TS}\left(\mathbf{V I}^{\delta \alpha, \delta \alpha}{ }_{7 \mathrm{CC}-\gamma(R)} \rightarrow \mathbf{V I I}^{\delta \alpha, \delta \alpha}{ }_{7 \mathrm{CC}-\gamma(R)}\right)\right)$, and $12.1 \mathrm{kcal}^{\mathrm{mol}}{ }^{-1}$ $\left(\mathrm{TS}\left(\mathbf{V I}^{\delta \alpha, \alpha \delta_{7 C C}-\gamma(R)} \rightarrow \mathbf{V I I}{ }^{\left.\delta \alpha, \alpha \delta_{7 C C}-\gamma(R)\right)}\right)\right.$ when the cleavage takes place on the less hindered oxygen-acyl $\mathrm{O}_{2}^{\prime}-\mathrm{C}(\mathrm{O})(\mathrm{O})$ bond. This process, as for the nucleophilic attack, is exergonic with respect to the previous intermediates, but remains endergonic with respect to the entrance channel, between 2.5 and $5.9 \mathrm{kcal}^{\mathrm{mol}}{ }^{-1}$. The resulting intermediates are characterized by the formation of $\mathrm{Zn}-\mathrm{O}$ bond between the metal centre and the endocyclic oxygen atom $\left(\mathrm{O}_{1}^{\prime}\right.$ for $\mathbf{V I I}{ }^{\alpha \delta, \delta \alpha}{ }_{7 \mathrm{CC}-\gamma(R)}$ and $\mathbf{V I I}{ }^{\alpha \delta, \alpha \delta}{ }_{7 \mathrm{CC}-\gamma(R)}$ or $\mathrm{O}_{2}^{\prime}$ for $\mathbf{V I I}{ }^{\delta \alpha, \delta \alpha}{ }_{7 \mathrm{CC}-\gamma(R)}$ and VII $\left.{ }^{\delta \alpha, \alpha \delta}{ }_{7 C C-\gamma(R)}\right)$ involved in the cleaved $\mathrm{O}_{\mathrm{x}}^{\prime}-\mathrm{C}(\mathrm{O})(\mathrm{O})$ bond $(\mathrm{x}=1$ or 2$)$, which ensures the coordination of the alkoxide growing chain to the metal centre. In all these cases, the metal centre exhibits a distorted tetrahedral environment with the 7CC- $\gamma(R)$ monomer fully opened. In the last step, the final products VIII ${ }^{\alpha \delta, \delta \alpha}{ }_{7 \mathrm{CC}-\gamma(R)}, \mathbf{V I I I}^{\delta \alpha, \delta \alpha}{ }_{7 \mathrm{CC}-\gamma(R)}, \mathbf{V I I I}^{\delta \alpha, \alpha \delta}{ }_{7 \mathrm{CC}-\gamma(R)}$ and VIII $^{\alpha \delta, \alpha \delta}{ }_{7 \mathrm{CC}-\gamma(R)}$ are obtained by decoordination of the carbonate arm via a low energy process, with an activation barrier calculated lower than $1.9 \mathrm{kcal}^{\mathrm{mol}} \mathrm{mol}^{-1}$ with respect to $\mathbf{V I I}{ }^{\alpha \delta, \delta \alpha}{ }_{7 \mathrm{CC}-\gamma(R)}$,

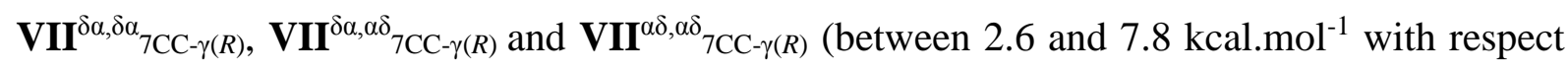
to the separated reactants). The formation of these final products is a slightly exergonic process, between 2.0 and $5.0 \mathrm{kcal} . \mathrm{mol}^{-1}$ with respect to $\mathbf{I V}^{\alpha \delta_{7 \mathrm{CC}-\gamma(R)}}$ and $\mathbf{I V}^{\delta \alpha}{ }_{7 \mathrm{CC}-\gamma(R)}$, giving an overall propagation step exergonic between 3.9 and $6.4 \mathrm{kcal}^{\mathrm{mol}}{ }^{-1}$ with respect to the 
separated reactants. According to this energy profile, the nucleophilic attack corresponds to the rate-limiting step. Analyzing in more detail the preferred kinetic pathway, it is noteworthy that the four transition states of the nucleophilic attack are quite similar within the precision of the computational method $\left(\mathrm{ca} .5 \mathrm{kcal} . \mathrm{mol}^{-1}\right) .{ }^{17}$ Thus, the four considered pathways leading to a growing polymer chain carrying methyl groups in $(\delta \alpha)(\delta \alpha),(\delta \alpha)(\alpha \delta),(\alpha \delta)(\delta \alpha)$ or $(\alpha \delta)(\alpha \delta)$ positions are competitive in a thermodynamic and kinetic point of view. These computational findings on the ROP of 7CC- $\gamma(R, r e)$ and $7 \mathrm{CC}-\gamma(R, s i)$ mediated by the zinc alkoxide complex $\left[\left(\mathrm{BDI}^{\mathrm{iPr}}\right) \mathrm{Zn}(\mathrm{OMe})\right]$, highlighting the competitive decoordination of the opened carbonate moiety from the zinc centre upon cleavage of the $\mathrm{ZnOC}(\mathrm{OMe})-\mathrm{O}_{2}$ or the $\mathrm{ZnOC}(\mathrm{OMe})-$ $\mathrm{O}_{1}(\mathrm{Me})$ bond in $\mathbf{I I}^{\alpha \delta_{7 C C}-\gamma(R, r e)}$ and $\mathbf{I I}^{\alpha \delta_{7 C C}-\gamma(R, s i)}$, can be compared to the experimental results. Note that, experimentally, only ROP of a racemic mixture of the two enantiomers, i.e. $(R, S)$ $7 \mathrm{CC}-\gamma \mathrm{Me}$, has been carried out with the $\left[\left(\mathrm{BDI}^{i \mathrm{Pr}}\right) \mathrm{Zn}\left(\mathrm{N}\left(\mathrm{SiMe}_{3}\right)_{2}\right)\right] / \mathrm{BnOH}$ and ${ }^{i} \mathrm{PrOH}$ catalyst systems. ${ }^{6 a}$ Detailed microstructural ${ }^{13} \mathrm{C}\left\{{ }^{1} \mathrm{H}\right\}$ NMR analyses of the poly $(7 \mathrm{CC}-\gamma \mathrm{Me})$ have evidenced some regioselectivity of such zinc- $\beta$-diketiminate alkoxide systems. At $20{ }^{\circ} \mathrm{C}$, the preferential ring-opening of the $7 \mathrm{CC}-\gamma \mathrm{Me}$ actually proceeds at the most hindered oxygen-acyl $\mathrm{O}_{1}-\mathrm{C}(\mathrm{O}) \mathrm{O}$ bond, i.e. the one closest to the $\mathrm{Me}$ substituent. The degree of regioselectivity

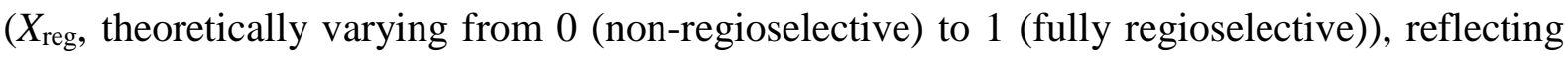
the affinity of these given zinc-BDI based catalyst systems to promote the $\mathrm{O}_{1}-$ acyl vs. $\mathrm{O}_{2}-$ acyl bond rupture, was also shown to decrease with increasing temperature, with $X_{\text {reg }}=0.71$ at $20{ }^{\circ} \mathrm{C}$ and 0.51 at $60{ }^{\circ} \mathrm{C} .{ }^{6 a}$ 

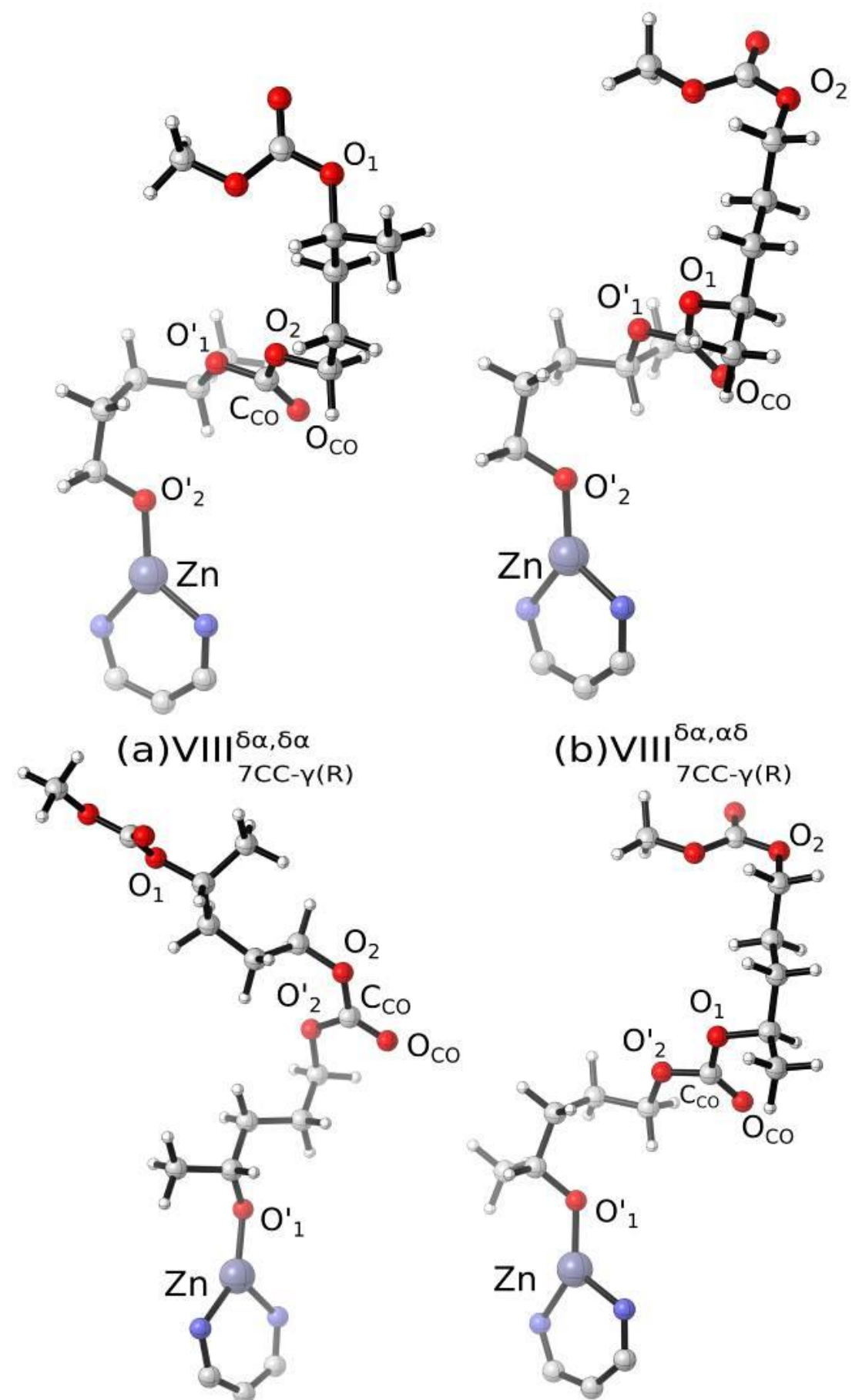

(b) VIII ${ }_{7 C C-\gamma(R)}^{\delta \alpha, \alpha \delta}$

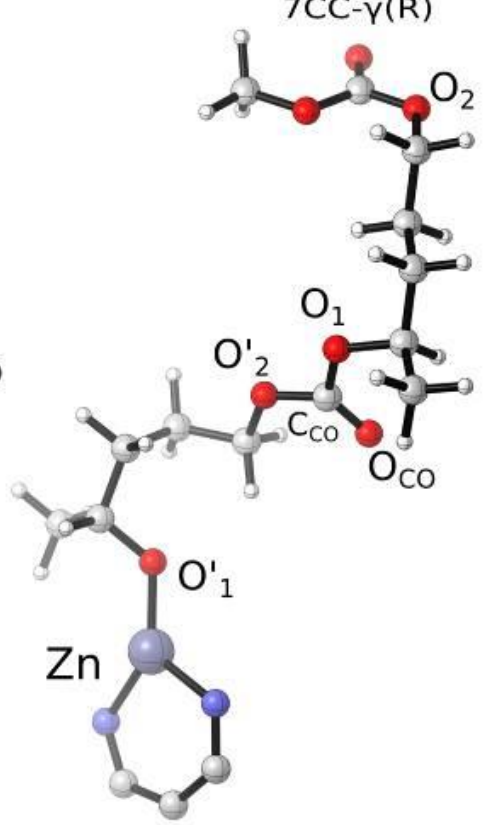

(C) $\mathrm{VIII}_{7 C C-\gamma(\mathrm{R})}^{\alpha \delta, \delta \alpha}$

(d) $\mathrm{VIII}{ }_{7 C C-\gamma(R)}^{\alpha \delta, \alpha \delta}$

Figure 11. Optimized structures of the propagation products of the ROP of 7CC- $\gamma(R)$ mediated by $\left[\left(\mathrm{BDI}^{\mathrm{iPr}}\right) \mathrm{Zn}(\mathrm{OMe})\right]$. In order to differentiate the two alkoxy oxygen atoms of the carbonate ester functional group, the oxygen atom closest to the substituted carbon atom is labelled $\mathrm{O}_{1}$; ; the other oxygen atom is then labelled $\mathrm{O}_{2}$. 


\subsection{Ring-opening polymerization of $\gamma$-substituted trimethylene carbonate}

\section{Initiation Step of the ROP of TMC- $\gamma$ Me.}

Experimentally, ROP of a racemic mixture of the related $\gamma$-methyl-substituted sixmembered ring TMC- $\gamma \mathrm{Me}$ with $\left[\left(\mathrm{BDI}^{i \mathrm{Pr}}\right) \mathrm{Zn}\left(\mathrm{N}\left(\mathrm{SiMe}_{3}\right)_{2}\right)\right] / \mathrm{BnOH}$ proceeds, as for $7 \mathrm{CC}-\gamma \mathrm{Me}$, with significant regioselectivity at the most hindered oxygen-acyl bond $\left(X_{\text {reg }}>0.98\right) .{ }^{6 \mathrm{~b}} \mathrm{~A}$ similar theoretical study was carried out. As for $7 \mathrm{CC}-\gamma(R)$ and $7 \mathrm{CC}-\gamma(S)$ compounds, the $\gamma$-substitution of one hydrogen atom of TMC by a methyl group leads to two enantiomers, TMC- $\gamma(R)$ and TMC- $\gamma(S)$. In the same way, due to the prochirality of the carbon atom of the $\mathrm{C}=\mathrm{O}$ bond, two enantiofaces, $r e$ and $s i$, exist for both TMC- $\gamma(R)$ and TMC- $\gamma(S)$ (Figure 12). The initiation step of the ROP has been computed considering each enantioface, i.e., TMC$\gamma(R, r e), \mathrm{TMC}-\gamma(R, s i), \mathrm{TMC}-\gamma(S, r e)$ and TMC- $\gamma(S, s i)$.

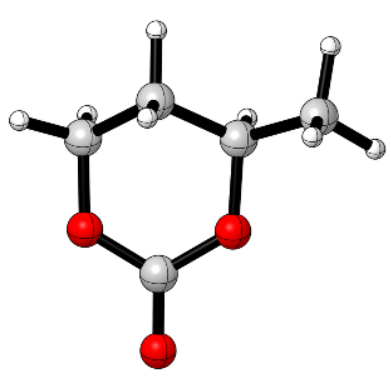

(a) TMC- $\gamma($ R,re $)$

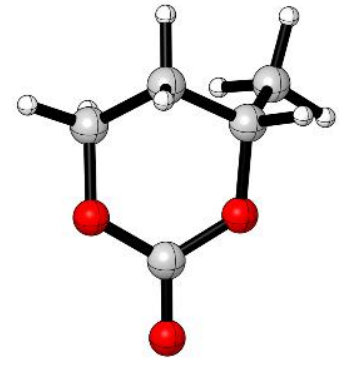

(b) TMC- $\gamma($ S,re $)$

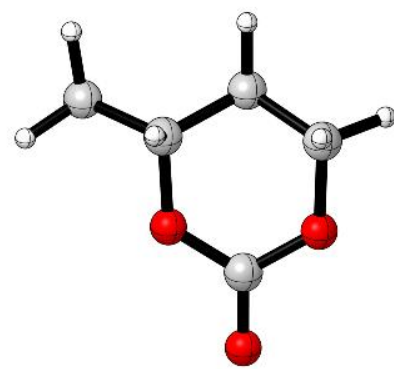

(c) TMC- $\gamma(R, s i)$

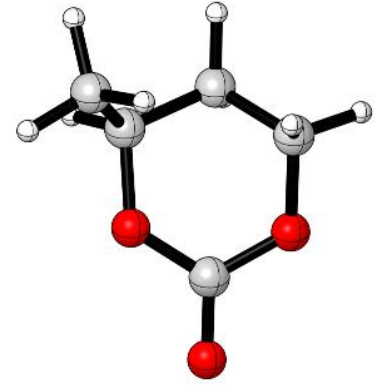

(d) $\mathrm{TMC}-\gamma(\mathrm{S}, \mathrm{si})$

Figure 12. Representation of the $r e$ and si enantiofaces of TMC- $\gamma(R)$ and TMC- $\gamma(S)$ enantiomers.

In the present case, similarly to $7 \mathrm{CC}-\gamma(R)$, the relative Gibbs-free energies of the intermediates and the activation barriers involved in the initiation reaction of the TMC- $\gamma(R)$ and TMC- $\gamma(S)$ ROP are very close (Table S2). According to this finding, only the ROP of TMC- $\gamma(R)$ mediated by $\left[\left(\mathrm{BDI}^{\mathrm{iPr}}\right) \mathrm{Zn}(\mathrm{OMe})\right]$ is next addressed. Thus, we have considered the 
nucleophilic attack on the $r e$ and si enantiofaces of TMC- $\gamma(R)$ and the tilting motion step from each nucleophilic attack product leading to four distinct pathways (Figure 13). The optimized structures of intermediates and transition states relevant for the initiation step of the ROP of TMC- $\gamma(R)$ are presented in Figures 14, 15 and 16. The key geometrical parameters are summarized in Table S4.

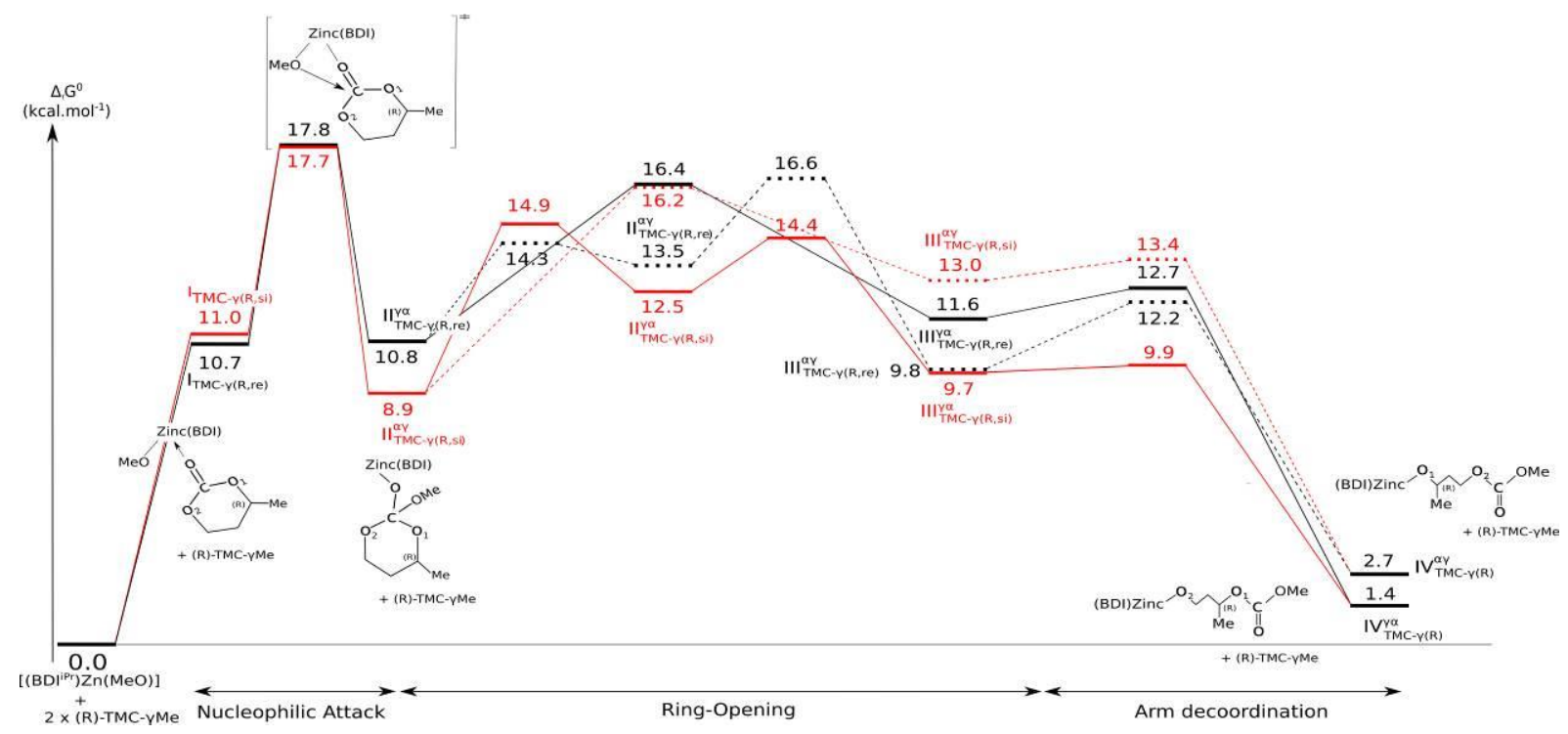

Figure 13. Calculated free-energy profile of the initiation step of the ROP of TMC- $\gamma(R)$ mediated by $\left[\left(\mathrm{BDI}^{\mathrm{iPr}}\right) \mathrm{Zn}(\mathrm{OMe})\right]$.

Similarly to the case of 7CC- $\gamma(R)$, the reaction begins in both cases with the formation of adducts, $\mathbf{I}_{\mathrm{TMC}-\gamma(R, r e)}$ and $\mathbf{I}_{\mathrm{TMC}-\gamma(R, s i)}$, endergonic by +10.7 and $+11.0 \mathrm{kcal}_{\mathrm{mol}}{ }^{-1}$, respectively, with respect to the separated reactants. The coordination of the TMC- $\gamma(R)$ molecule is similar to that found with 7CC- $\gamma(R)$, i.e., the TMC- $\gamma(R)$ monomer is coordinated to the zinc atom by its exocyclic oxygen atom $\left(\mathrm{Zn}-\mathrm{O}_{\mathrm{CO}}\right.$ distances around $2.26 \AA$ ). From these adducts, the nucleophilic attack of the methoxy moiety to the carbonyl carbon $\mathrm{C}_{\mathrm{CO}}$ can take place either on the $r e\left(\mathbf{T S}\left(\mathbf{I}_{\mathrm{TMC}-\gamma(R, r e)} \rightarrow \mathbf{I I}^{\gamma \alpha} \mathrm{TM}-\gamma(R, r e)\right)\right)$ or the si $\left(\mathbf{T S}\left(\mathbf{I}_{\mathrm{TMC}-\gamma(R, s i)} \rightarrow \mathbf{I I}^{\alpha \gamma}{ }_{\mathrm{TMC}-\gamma(R, s i)}\right)\right)$ enantioface. These attacks lead to the formation of two intermediates $\mathbf{I I}^{\gamma \alpha} \mathrm{TMC}-\gamma(R, r e)$ and $\mathbf{I I}^{\alpha \gamma} \mathrm{TMC}-\gamma(R, s i)$, for the nucleophilic attack on the re and si enantiofaces of TMC- $\gamma(R)$, respectively, with an energy 
barrier around $+17.8 \mathrm{kcal} . \mathrm{mol}^{-1}$ in both cases. The formation of $\mathbf{I I}^{\gamma \alpha} \mathrm{TMC}-\gamma(R, r e)$ and $\mathbf{I I}^{\alpha \gamma} \mathrm{TMC}-\gamma(R, s i)$ are found endergonic with respect to the entrance channel $\left(+10.8\right.$ and +8.9 kcal.mol ${ }^{-1}$, respectively). The geometrical similarity between both intermediates is in good agreement with the small energy difference of these two intermediates. Indeed, in both cases, the $\mathrm{C}_{\mathrm{CO}}-$ OCO distance is elongated with respect to $\mathbf{I}_{\mathrm{TMC}-\gamma(R, r e)}$ and $\mathbf{I}_{\mathrm{TMC}-\gamma(R, s i)}$ (from 1.22 to $1.34 \AA$ ), which is coherent with the presence of a single bond between $\mathrm{C}_{\mathrm{CO}}$ and $\mathrm{O}_{\mathrm{CO}}$. In the same way, the $\mathrm{Zn}-\mathrm{O}_{\mathrm{CO}}$ distance is shortened from 2.26 to $1.86 \AA$ and a $\mathrm{C}_{\mathrm{CO}}-\mathrm{O}_{\mathrm{OMe}}$ single bond is formed in both cases. It is also noteworthy that, for $\mathbf{I I}^{\gamma \alpha} \mathrm{TMC}-\gamma(R, r e)$, the $\mathrm{Zn}-\mathrm{O}_{1}$ distance is longer than the $\mathrm{Zn}-\mathrm{O}_{2}$ distance while for $\mathbf{I I}^{\alpha \gamma} \mathrm{TMC}-\gamma(R, s i)$ the $\mathrm{Zn}-\mathrm{O}_{1}$ distance is shorter than the $\mathrm{Zn}-\mathrm{O}_{2}$ distance in agreement with the formation of the final $\gamma \alpha$ and $\alpha \gamma$ products, respectively. From $\mathbf{I I}^{\gamma \alpha}$ TMC$\gamma(R, r e)$ and $\mathbf{I I}^{\alpha \gamma} \mathrm{TMC}-\gamma(R, s i)$, the formation of the final $\mathbf{I V}^{\gamma \alpha}{ }_{\mathrm{TMC}-\gamma(R)}$ and $\mathbf{I V}^{\alpha \gamma} \mathrm{TMC}-\gamma(R)$ products proceeds in two steps, i.e., the ring-opening followed by the concomitant decoordination of the carbonate ester arm. The ring-opening step leads, via an accessible transition state which lies +5.6 and +7.3 kcal.mol ${ }^{-1}$ above $\mathbf{I I}^{\gamma \alpha}{ }_{\mathrm{TMC}-\gamma(R, r e)}$ and $\mathbf{I I}^{\alpha \gamma} \mathrm{TMC}-\gamma(R, s i)$, to an endergonic

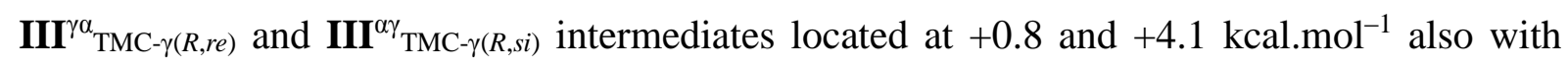
respect to $\mathbf{I I}^{\gamma \alpha}{ }_{\mathrm{TMC}-\gamma(R, r e)}$ and $\mathbf{I I}^{\alpha \gamma} \mathrm{TMC}-\gamma(R, s i)$. Finally, the decoordination of the carbonate ester arm and relaxation of the opened-chain leads to the final $\mathbf{I} \mathbf{V}^{\gamma \alpha}{ }_{\mathrm{TMC}-\gamma(R)}$ and $\mathbf{I V}^{\alpha \gamma} \mathrm{TMC}_{-\gamma(R)}$ products located at +1.4 and $+2.7 \mathrm{kcal}^{\mathrm{mol}} \mathrm{m}^{-1}$ with respect to the entrance channel. This decoordination

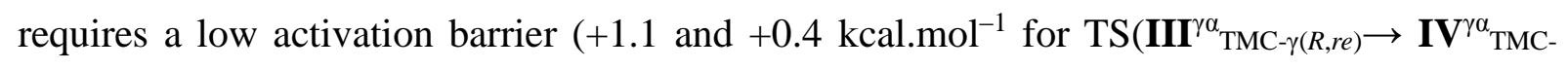
$\gamma(R))$ and $\mathrm{TS}\left(\mathbf{I I I}^{\alpha \gamma} \mathrm{TMC}_{-\gamma(R, s i)} \rightarrow \mathbf{I V}^{\alpha \gamma} \mathrm{TMC}_{-\gamma(R)}\right)$ with respect to $\mathbf{I I I}^{\gamma \alpha} \mathrm{TMC}_{-\gamma(R, r e)}$ and III $^{\alpha \gamma} \mathrm{TMC}-\gamma(R, s i)$, respectively. On the basis of these results, both of these pathways represent a feasible mechanism for the initiation reaction. Indeed, the reaction is, from a thermodynamic point of view, a slightly endergonic process with the highest energy transition state located at +17.8 kcal.mol ${ }^{-1}$ above the entrance channel, leading, as for $7 \mathrm{CC}-\gamma(R)$, to an overall facile reaction. We also examined a second possibility, in which, from $\mathbf{I I}^{\gamma \alpha}{ }_{\mathrm{TMC}-\gamma(R, r e)}$ and $\mathbf{I I}^{\alpha \gamma} \mathrm{TMC}-\gamma(R, s i)$, instead of the ring-opening, a tilting motion step occurs. This step replaces the interaction between 
the metal centre and the endocyclic oxygen atom $\left(\mathrm{Zn}-\mathrm{O}_{2}\right.$ for $\mathbf{I I}^{\gamma \alpha}{ }_{\mathrm{TMC}-\gamma(R, r e)}$ and $\mathrm{Zn}-\mathrm{O}_{1}$ for $\left.\mathbf{I I}^{\alpha \gamma} \mathrm{TMC}-\gamma(R, s i)\right)$ by a new interaction between the metal center and the second endocyclic oxygen atom $\left(\mathrm{Zn}-\mathrm{O}_{1}\right.$ for $\mathbf{I I}^{\gamma \alpha}{ }_{\mathrm{TMC}-\gamma(R, r e)}$ and $\mathrm{Zn}-\mathrm{O}_{2}$ for $\left.\mathbf{I I}^{\alpha \gamma}{ }_{\mathrm{TMC}-\gamma(R, \mathrm{si})}\right)$, i.e., the formation of $\mathbf{I I}^{\alpha \gamma} \mathrm{TMC}-\gamma(R, r e)$ from $\mathbf{I I}^{\gamma \alpha}{ }_{\mathrm{TMC}-\gamma(R, r e)}$ and $\mathbf{I I}^{\gamma \alpha}{ }_{\mathrm{TMC}-\gamma(R, s i)}$ from $\mathbf{I I}^{\alpha \gamma} \mathrm{TMC}-\gamma(R, s i)$. As for 7CC- $\gamma(R)$, this step is kinetically accessible with a low activation barrier of +3.5 and $+6.0 \mathrm{kcal}^{\mathrm{mol}}{ }^{-1}$ with respect to $\mathbf{I I}^{\gamma \alpha}{ }_{\mathrm{TMC}-\gamma(R, r e)}$ and $\mathbf{I I}^{\alpha \gamma}{ }_{\mathrm{TMC}-\gamma(R, s i)}$. Also, the two intermediates $\mathbf{I I}^{\alpha \gamma}{ }_{\mathrm{TMC}-\gamma(R, r e)}$ and $\mathbf{I I}^{\gamma \alpha}{ }_{\mathrm{TMC}-\gamma(R, s i)}$ are

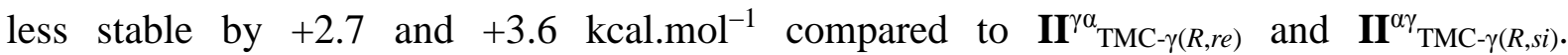
Nevertheless, from $\mathbf{I I}^{\alpha \gamma}{ }_{\mathrm{TMC}-\gamma(R, r e)}$ and $\mathbf{I I}{ }^{\gamma \alpha} \mathrm{TMC}-\gamma(R, s i)$, the two final $\mathbf{I} \mathbf{V}^{\alpha \gamma} \mathrm{TMC}_{-\gamma(R)}$ and $\mathbf{I V}{ }^{\gamma \alpha} \mathrm{TMC}-\gamma(R)$ products can also be obtained through a ring-opening step followed by the concomitant decoordination of the carbonate ester arm. Detailed analysis of the activation barriers for these two steps from $\mathbf{I I}^{\alpha \gamma}{ }_{\mathrm{TMC}-\gamma(R, r e)}$ and $\mathbf{I I}^{\gamma \alpha}{ }_{\mathrm{TMC}-\gamma(R, s i)}$, shows similar results to those obtained above from $\mathbf{I I}^{\gamma \alpha}{ }_{\mathrm{TMC}-\gamma(R, r e)}$ and $\mathbf{I I}^{\alpha \gamma}{ }_{\mathrm{TMC}-\gamma(R, s i)}$. Thus, the two final products can result from any of the two possible pathways (with or without a tilting motion step). 


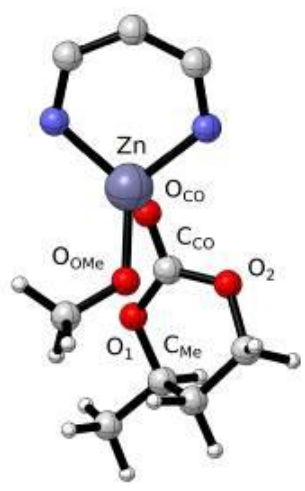

a) $I_{T M C-\gamma(R, r e)}$

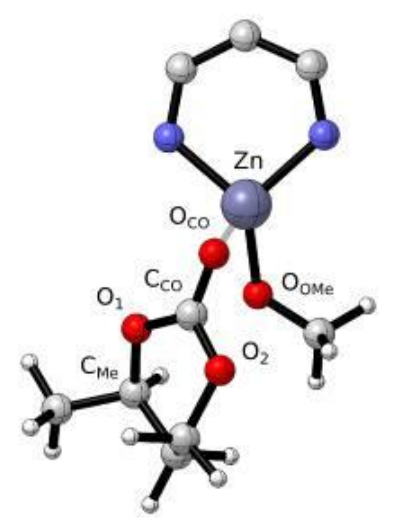

d) $I_{T M C-Y(R, s i)}$

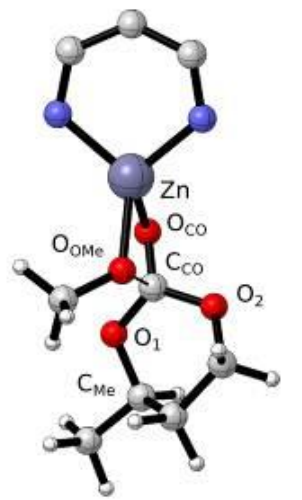

b) TS

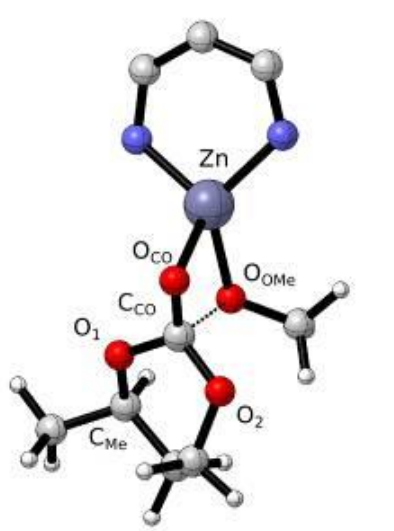

e) $T S_{I_{T M C \cdot Y(R, s i)} \rightarrow I_{T M C \cdot y(R, s i)}^{a r}}$
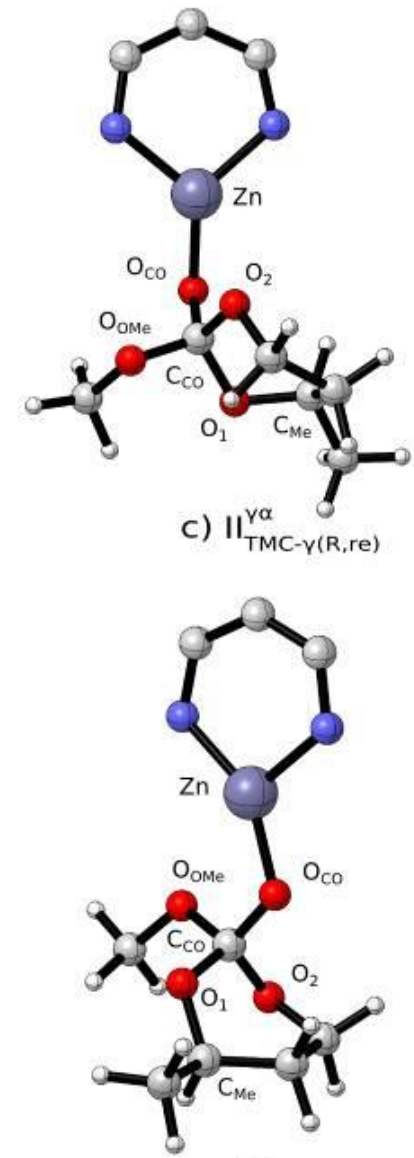

f) $I_{T M C-\gamma(R, s i)}^{\alpha \gamma}$

Figure 14. Optimized structures of complexes involved in the nucleophilic attack step of the ROP of TMC- $\gamma(R, r e)$ and $\mathrm{TMC}-\gamma(R, s i)$ mediated by $\left[\left(\mathrm{BDI}^{\mathrm{iPr}}\right) \mathrm{Zn}(\mathrm{OMe})\right]$. The BDI complex has been partially omitted for clarity. In order to differentiate the two alkoxy oxygen atoms of the carbonate ester functional group, the oxygen atom closest to the substituted carbon atom is labelled $\mathrm{O}_{1}$; the other oxygen atom is then labelled $\mathrm{O}_{2}$. 


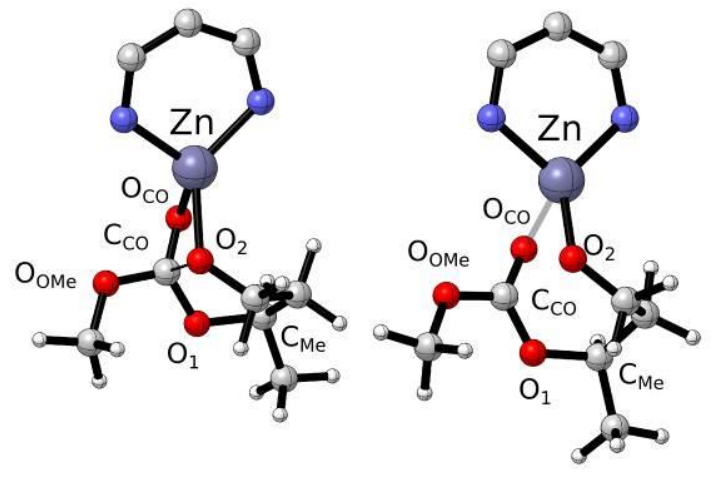

a) $T S_{\|_{T M C-\gamma(R, r e)}^{\gamma \alpha}} \rightarrow \|_{T M C-\gamma(R, r e)}^{\gamma \alpha}$

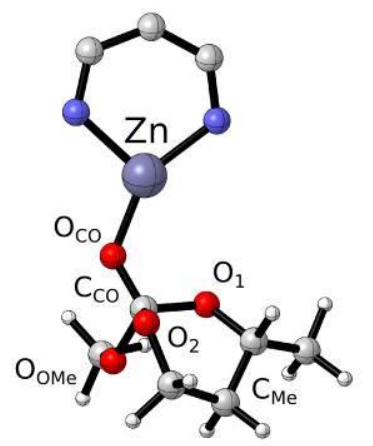

e) $T S_{\|}^{\gamma M C-\gamma(R, r e)} \rightarrow \|_{T M C-\gamma(R, r e)}^{\alpha \gamma}$

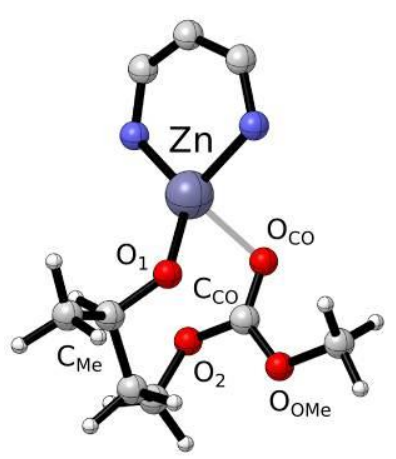

h) $I I_{T M C-\gamma(R, r e)}^{\alpha \gamma}$ b) III ${ }_{T M C-\gamma(R, r e)}^{\gamma \alpha}$

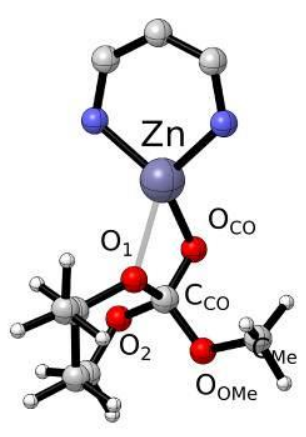

f) $\operatorname{II}_{\mathrm{TMC}-\mathrm{\gamma}(\mathrm{R}, \mathrm{re})}$

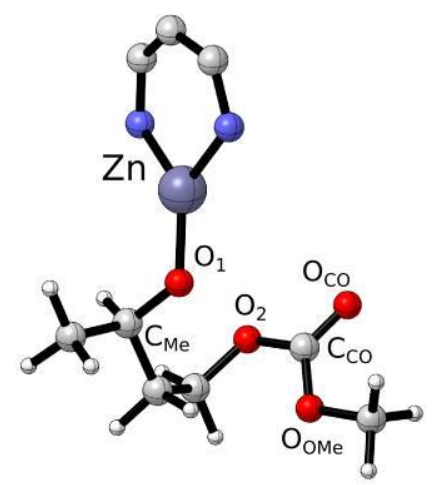

i) $T S_{I I I M C-\gamma(R, r e)}^{\alpha \gamma} I_{T M C-\gamma(R)}^{\alpha \gamma}$

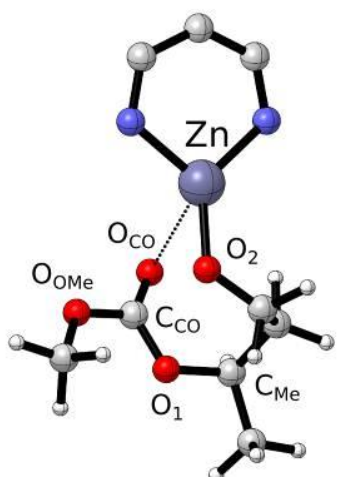

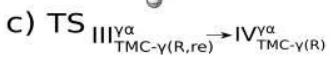

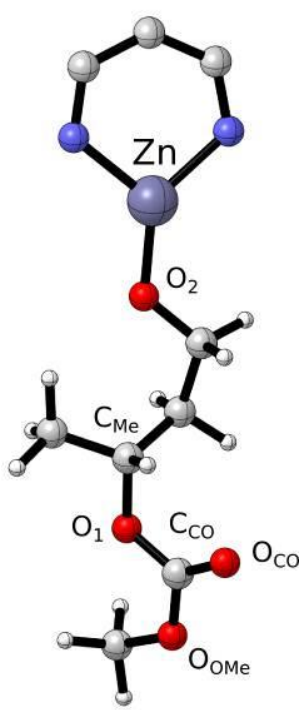

d) $I_{T M C-\gamma(R)}^{\gamma \alpha}$

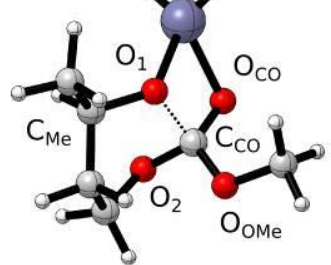

g) TS $\left\|I_{T M C-\gamma(R, \text { re })}^{\alpha \gamma} \rightarrow\right\| \|_{T M C-\gamma(R, \text { re })}^{\alpha \gamma}$

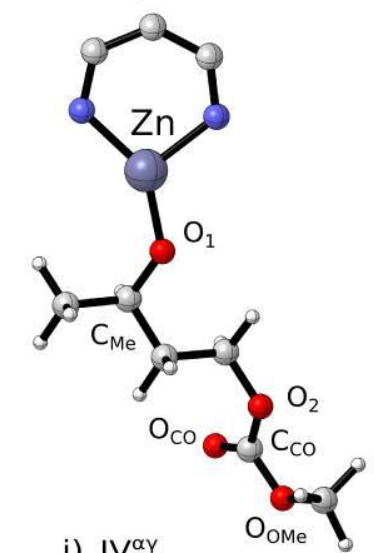

j) $I V_{T M C-\gamma(R)}^{\alpha \gamma}$

Figure 15. Optimized structures of complexes involved in the ring-opening and decoordination arm steps of the ROP of $\mathrm{TMC}-\gamma(R, r e)$ mediated by $\left[\left(\mathrm{BDI}^{\mathrm{iPr}}\right) \mathrm{Zn}(\mathrm{OMe})\right]$. The BDI complex has been partially omitted for the sake of clarity. 


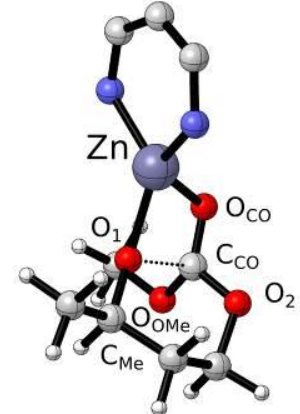

a) $T S_{\| I_{T M}^{\alpha \gamma}}$

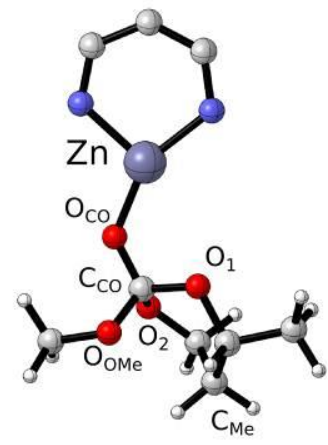

d) $T S\left\|_{T M C-\gamma(R, S i)}^{\alpha \gamma} \rightarrow\right\|_{T M C-\gamma(R, s i)}^{\gamma \alpha}$

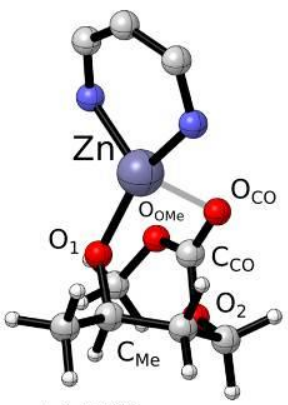

b) III ${ }_{\mathrm{TMC}-\mathrm{\gamma}(\mathrm{R}, \mathrm{si})}^{\alpha}$

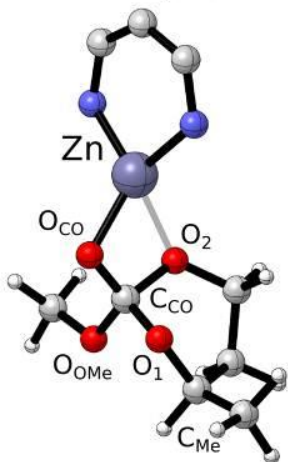

e) $\operatorname{II}_{T M C-\gamma(R, s i)}^{\gamma \alpha}$

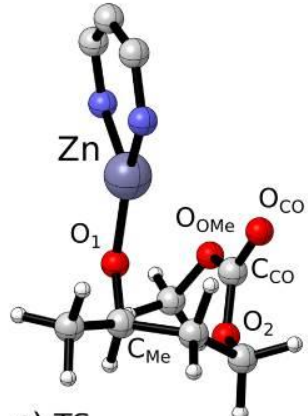

C) $T S_{I I I-\alpha \gamma C-\gamma(R, S i)} \rightarrow V_{T M C-\gamma(R)}^{\alpha \gamma}$

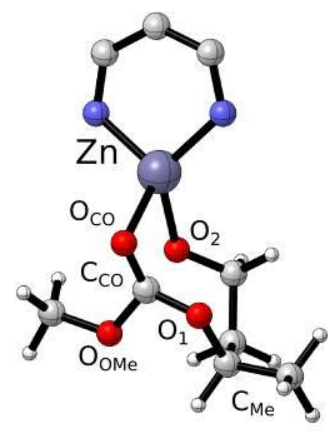

f) $T S_{\|_{T M C-\gamma(R, s i)}^{\gamma \alpha}} \rightarrow \|_{T M C-\gamma(R, s i)}^{\gamma \alpha \alpha}$

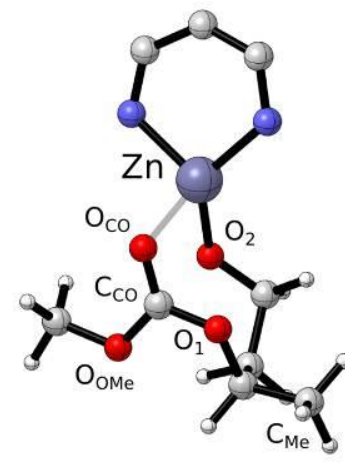

g) ${ }_{11}^{\gamma \alpha}{ }_{T M C-\gamma(R, s i)}^{\gamma \alpha}$

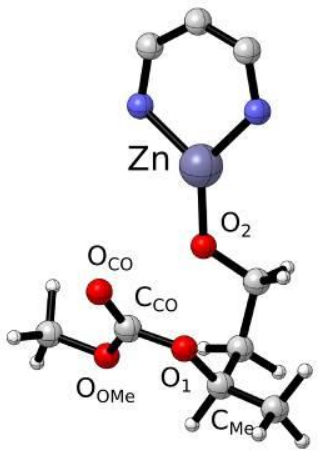

h) $T S I_{T M C-\gamma(R, s i)}^{\gamma \alpha} \rightarrow I V_{T M C-\gamma(R)}^{\gamma \alpha}$

Figure 16. Optimized structures of complexes involved in the ring-opening and decoordination arm steps of step of the ROP of TMC- $\gamma(R, s i)$ mediated by [(BDI $\left.\left.{ }^{\mathrm{iPr}}\right) \mathrm{Zn}(\mathrm{OMe})\right]$. The BDI complex has been partially omitted for the sake of clarity.

\section{Propagation Step of the ROP of TMC- $\gamma(R)$.}

The second carbonate insertion, corresponding to the first propagation step, has been computed as a representation of the polymer propagation. The energy profile computed for the first propagation step is depicted in Figure 17. In each case, as for 7CC- $\gamma(R)$, the Gibbsfree energies for intermediates and transitions states $\left(\mathrm{kcal} . \mathrm{mol}^{-1}\right)$ are relative to the total 
Gibbs-free energies of reactants (i.e., $\left.\left[\left(\mathrm{BDI}^{\mathrm{iPr}}\right) \mathrm{Zn}(\mathrm{OMe})\right]+2 \mathrm{TMC}-\gamma(R)\right)$. The optimized structures of the relevant stationary points of the potential energy surface and the key geometrical parameters of these points are shown in Figures 18, S3 and S4.

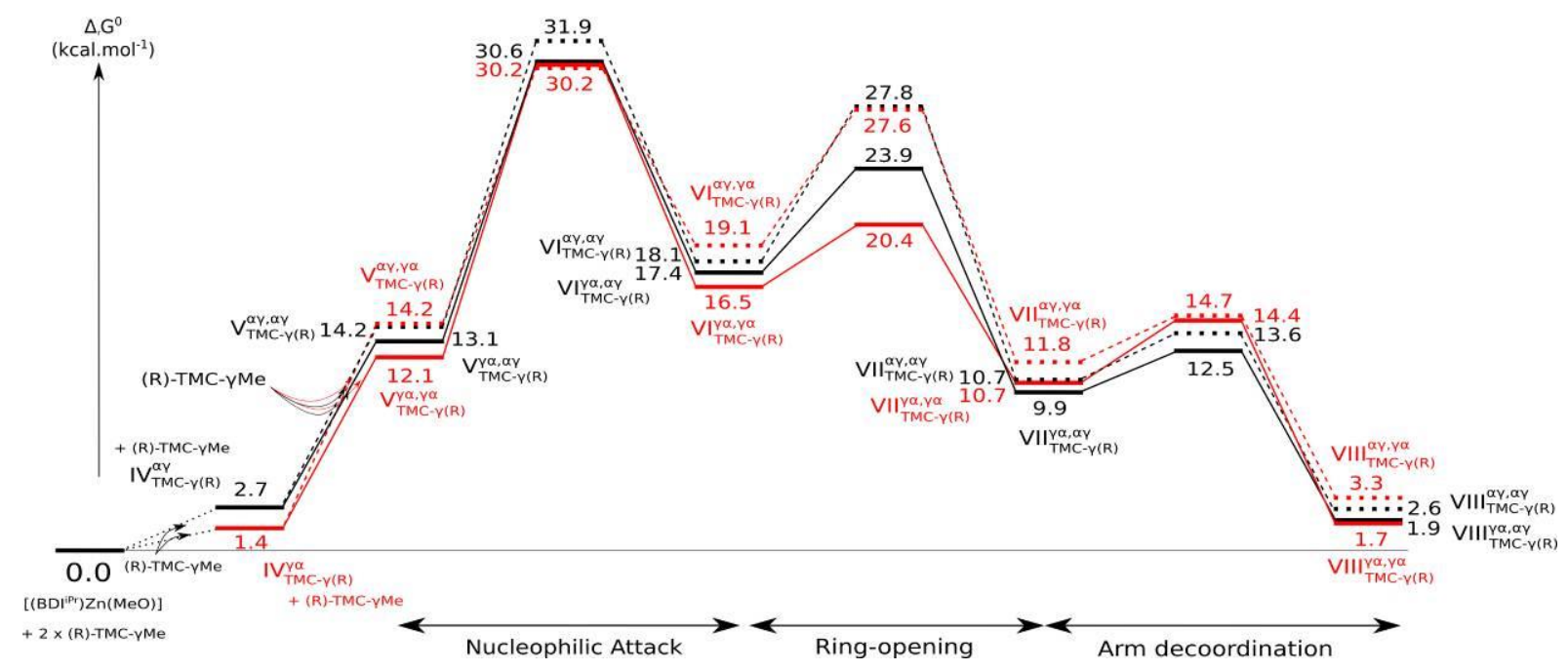

Figure 17. Calculated Gibbs-free energy profile of the propagation step of the ROP of TMC$\gamma(R)$ mediated by $\left[\left(\mathrm{BDI}^{\mathrm{iPr}}\right) \mathrm{Zn}(\mathrm{OMe})\right]$.

The insertion of the second TMC- $\gamma(R)$ molecule, as for the initiation step, occurs according to a three-step process: first, a nucleophilic attack of the alkoxide group followed by the ring-opening of the tetrahedral intermediate and finally the decoordination of the carbonate arm. As for the computed second 7CC- $\gamma(R)$ insertion, from each of the two initiation products $\left(\mathbf{I V}^{\gamma \alpha}{ }_{\mathrm{TMC}-\gamma(R)}\right.$ and $\left.\mathbf{I} \mathbf{V}^{\alpha \gamma} \mathrm{TMC}-\gamma(R)\right)$, there are two possibilities for the propagation step. Indeed, from IV ${ }^{\gamma \alpha}{ }_{\mathrm{TMC}-\gamma(R)}$ and $\mathbf{I V}{ }^{\alpha \gamma}{ }_{\mathrm{TMC}-\gamma(R)}$, the insertion of the second TMC$\gamma(R)$ molecule can lead to a growing polymer chain carrying a methyl group at the $\gamma$ position with respect to the oxygen atom coordinated to the metal centre and therefore in $\alpha$ position of the oxygen atom of the carbonate ester group (VIII ${ }^{\gamma \alpha, \gamma \alpha}{ }_{\mathrm{TMC}-\gamma(R)}$ Figure 18a and VIII ${ }^{\gamma \alpha, \alpha \gamma} \mathrm{TMC}-\gamma(R)$ Figure $18 \mathrm{~b}$ ) or in $\alpha$ and $\gamma$ position with respect to the same oxygen atoms (VIII ${ }^{\alpha \gamma, \gamma \alpha}{ }_{\mathrm{TMC}-\gamma(R)}$ Figure $18 \mathrm{c}$ and VIII ${ }^{\alpha \gamma, \alpha \gamma}{ }_{\mathrm{TMC}-\gamma(R)}$ Figure 18d). The first propagation step begins by the coordination of a second TMC- $\gamma(R)$ monomer to $\mathbf{I} \mathbf{V}^{\gamma \alpha} \mathrm{TMC}-\gamma(R)$ and $\mathbf{I} \mathbf{V}^{\alpha \gamma} \mathrm{TMC}-\gamma(R)$, leading to the 
formation of four endergonic adducts $\mathbf{V}^{\gamma \alpha, \gamma \alpha}{ }_{\mathrm{TMC}-\gamma(R)}, \quad \mathbf{V}^{\alpha \gamma, \gamma \alpha}{ }_{\mathrm{TMC}-\gamma(R)}, \quad \mathbf{V}^{\gamma \alpha, \alpha \gamma} \mathrm{TMC}-\gamma(R)$ and $\mathbf{V}^{\alpha \gamma, \alpha \gamma}{ }_{\text {TMC- } \gamma(R)}$. The nucleophilic attack of the oxygen atom of the alkoxide growing chain to the carbonyl carbon $\mathrm{C}_{\mathrm{CO}}$ of the second $\mathrm{TMC}-\gamma(R)$ proceeds through the transition states $\mathrm{TS}\left(\mathbf{V}^{\gamma \alpha, \gamma \alpha}{ }_{\mathrm{TMC}-\gamma(R)} \rightarrow \quad \mathbf{V I}^{\gamma \alpha, \gamma \alpha}{ }_{\mathrm{TMC}-\gamma(R)}\right), \quad \mathrm{TS}\left(\mathbf{V}^{\alpha \gamma, \gamma \alpha}{ }_{\mathrm{TMC}-\gamma(R)} \rightarrow \mathbf{V I} \mathbf{I}^{\alpha \gamma, \gamma \alpha}{ }_{\mathrm{TMC}-\gamma(R)}\right), \quad \mathrm{TS}\left(\mathbf{V}^{\gamma \alpha, \alpha \gamma}{ }_{\mathrm{TMC}-}\right.$ $\left.\gamma(R) \rightarrow \mathbf{V I}{ }^{\gamma \alpha, \alpha \gamma} \mathrm{TMC}_{-\gamma(R)}\right)$ and $\mathrm{TS}\left(\mathbf{V}^{\alpha \gamma, \alpha \gamma} \mathrm{TMC}_{-\gamma(R)} \rightarrow \mathbf{V I} \mathbf{I}^{\alpha \gamma, \alpha \gamma} \mathrm{TMC}-\gamma(R)\right)$ affording the formation of intermediates VI ${ }^{\gamma \alpha, \gamma \alpha}{ }_{\mathrm{TMC}-\gamma(R)}, \mathbf{V} \mathbf{I}^{\alpha \gamma, \gamma \alpha}{ }_{\mathrm{TMC}-\gamma(R)}, \mathbf{V} \mathbf{I}^{\gamma \alpha, \alpha \gamma}{ }_{\mathrm{TMC}-\gamma(R)}$ and $\mathbf{V} \mathbf{I}^{\alpha \gamma, \alpha \gamma}{ }_{\mathrm{TMC}-\gamma(R)}$ with activation barriers between 30.2 and $31.9 \mathrm{kcal} . \mathrm{mol}^{-1}$. The formation of the different intermediates remains endergonic with respect to both the respective previous adducts (between 1.5 and 7.0 kcal.mol ${ }^{-1}$ ) and the entrance channel (between 16.5 and $19.1 \mathrm{kcal}^{\mathrm{mol}}{ }^{-1}$ ). In a previous work, ${ }^{8}$ we have studied the initiation and the first propagation step of the ROP of non-substituted TMC showing that the initiation and the second insertion step of the ROP of this monomer proceed at a similar rate (i.e., similar energy barriers and reaction energies). However, it is noteworthy that the presence of a $\gamma$-methyl substituent, and consequently the increase of the steric hindrance around the metal centre, induces an increase of the activation barriers of the first two steps of the second carbonate insertion, i.e., the nucleophilic attack (ca. 17.8 kcal.mol ${ }^{-1}$ vs. ca. $30.7 \mathrm{kcal}_{\mathrm{mol}}{ }^{-1}$ ) and the ring-opening (between 14.9 and $16.4 \mathrm{kcal} . \mathrm{mol}^{-1} v s$. between 20.4 and $27.8 \mathrm{kcal}^{\mathrm{mol}}{ }^{-1}$ ). For the first propagation step, as for the initiation step, the nucleophilic attack corresponds to the rate-limiting step of an overall accessible reaction. From a geometrical point of view, concomitant with the formation of the $\mathrm{O}_{1}-\mathrm{C}_{\mathrm{CO}}$ (for $\mathbf{V I}{ }^{\gamma \alpha, \alpha \gamma}{ }_{\mathrm{TMC}-\gamma(R)}$ and $\mathbf{V I}{ }^{\alpha \gamma, \alpha \gamma}{ }_{\mathrm{TMC}-\gamma(R)}$ ) or $\mathrm{O}_{2}-\mathrm{C}_{\mathrm{CO}}$ (for $\mathbf{V} \mathbf{I}^{\gamma \alpha, \gamma \alpha}{ }_{\mathrm{TMC}-\gamma(R)}$ and $\mathbf{V} \mathbf{I}^{\alpha \gamma, \gamma \alpha}{ }_{\mathrm{TMC}-\gamma(R)}$ ) bonds, the $\mathrm{Zn}-\mathrm{O}_{\mathrm{CO}}$ bond lengths are reduced sequentially from around $2.27 \AA$ in the different adducts to around $2.01 \AA$ in the corresponding transition states, and finally to around $1.85 \AA$ in the formed intermediates. The $\mathrm{C}_{\mathrm{CO}}-\mathrm{O}_{\mathrm{CO}}$ bond is continually elongated from $1.22 \AA$ in the different adducts to $1.34 \AA$ in the respective intermediates, which is in line with a single bond between these two atoms. Ring-opening occurs through $\operatorname{TS}\left(\mathbf{V I}{ }^{\gamma \alpha, \gamma \alpha}{ }_{\mathrm{TMC}-\gamma(R)} \rightarrow \mathbf{V I I}{ }^{\gamma \alpha, \gamma \alpha}{ }_{\mathrm{TMC}-\gamma(R)}\right)$, $\mathrm{TS}\left(\mathbf{V I}{ }^{\alpha \gamma, \gamma \alpha}{ }_{\mathrm{TMC}-\gamma(R)} \rightarrow \mathbf{V I I}{ }^{\alpha \gamma, \gamma \alpha}{ }_{\mathrm{TMC}-\gamma(R)}\right), \quad \mathrm{TS}\left(\mathbf{V I}^{\gamma \alpha, \alpha \gamma}{ }_{\mathrm{TMC}-\gamma(R)} \rightarrow \mathbf{V I I}{ }^{\gamma \alpha, \alpha \gamma}{ }_{\mathrm{TMC}-\gamma(R)}\right)$ and $\operatorname{TS}\left(\mathbf{V I}{ }^{\alpha \gamma, \alpha \gamma}{ }_{\mathrm{TMC}-}\right.$ 31 
$\left.\gamma(R) \rightarrow \mathbf{V I I}{ }^{\alpha \gamma, \alpha \gamma} \mathrm{TMC}-\gamma(R)\right)$. As aforementioned, the calculated Gibbs-free energy activation barriers for the ring-opening of TMC- $\gamma(R)$ are between 20.4 and $27.8 \mathrm{kcal}^{\mathrm{mol}}{ }^{-1}$. In this case, as previously observed for the first propagation step of the ROP of 7CC- $\gamma(R)$, the steric repulsion between the $\beta$-diketiminate ligand and the growing polymer chain induces a higher activation barrier when the cleavage of the oxygen-acyl bond takes place on the most

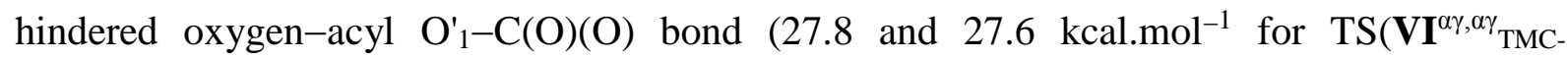

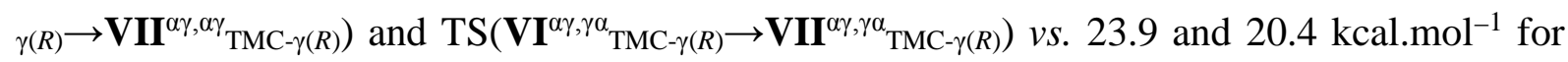
$\mathrm{TS}\left(\mathbf{V I}{ }^{\gamma \alpha, \alpha \gamma}{ }_{\mathrm{TMC}-\gamma(R)} \rightarrow \mathbf{V I I}{ }^{\gamma \alpha, \alpha \gamma}{ }_{\mathrm{TMC}-\gamma(R)}\right) \quad$ and $\quad \mathrm{TS}\left(\mathbf{V I}^{\gamma \alpha, \gamma \alpha}{ }_{\mathrm{TMC}-\gamma(R)} \rightarrow \mathbf{V I I}{ }^{\gamma \alpha, \gamma \alpha}{ }_{\mathrm{TMC}-\gamma(R)}\right)$, respectively). Following the intrinsic reaction coordinate, the unstable intermediates $\mathbf{V I I}^{\alpha \gamma, \alpha \gamma}{ }_{\mathrm{TMC}-\gamma(R)}$, VII $^{\alpha \gamma, \gamma \alpha}{ }_{\mathrm{TMC}-\gamma(R)}, \mathbf{V I I}^{\gamma \alpha, \alpha \gamma} \mathrm{TMC}-\gamma(R)$ and VII ${ }^{\gamma \alpha, \gamma \alpha}{ }_{\mathrm{TMC}-\gamma(R)}$ are formed, which, in turn, lead to the final VIII $^{\alpha \gamma, \alpha \gamma}{ }_{\mathrm{TMC}-\gamma(R)}$, VIII $^{\alpha \gamma, \gamma \alpha}{ }_{\mathrm{TMC}-\gamma(R)}$, VIII $^{\gamma \alpha, \alpha \gamma}{ }_{\mathrm{TMC}-\gamma(R)}$ and VIII' ${ }^{\gamma \alpha, \gamma \alpha}{ }_{\mathrm{TMC}-\gamma(R)}$ products, via a low energy process, corresponding to the decoordination of the carbonate arm, with an activation barrier calculated to be between +2.6 and $3.4 \mathrm{kcal}^{\mathrm{mol}}{ }^{-1}$ with respect to the previous intermediates (between +12.5 and $14.7 \mathrm{kcal} \mathrm{mol}^{-1}$ with respect to the separated reactants). In contrast to the slightly endergonic first insertion step $\left(+1.2 \mathrm{kcal}^{\mathrm{mol}}{ }^{-1}\right.$ for $\mathbf{I V}^{\gamma \alpha}{ }_{\mathrm{TMC}-\gamma(R)}$ and +2.7 kcal.mol ${ }^{-1} \mathbf{I V}^{\alpha \gamma} \mathrm{TMC}_{-\gamma(R)}$ with respect to the entrance channel), the second insertion step is in all the cases an athermic, or even a slightly exergonic process $\left(+0.3 \mathrm{kcal} . \mathrm{mol}^{-1}\right.$ for VIII $^{\gamma \alpha, \gamma \alpha}{ }_{\mathrm{TMC}-\gamma(R)},+1.9 \mathrm{kcal}^{\mathrm{m}} \mathrm{mol}^{-1}$ for VIII ${ }^{\alpha \gamma, \gamma \alpha} \mathrm{TMC}-\gamma(R),-0.1 \mathrm{kcal}^{-\mathrm{mol}^{-1}}$ for VIII ${ }^{\alpha \gamma, \alpha \gamma} \mathrm{TMC}_{-\gamma(R)}$ and -0.8 kcal.mol ${ }^{-1}$ for VIII ${ }^{\gamma \alpha, \alpha \gamma}{ }_{\mathrm{TMC}-\gamma(R)}$, with respect to the first insertion products). Thus, the polymerization of TMC- $\gamma(R)$ mediated by $\left[\left(\mathrm{BDI}^{\mathrm{iPr}}\right) \mathrm{Zn}(\mathrm{OMe})\right]$ is computed to be a kinetically accessible, although quite energy demanding athermic process. Thus, the four considered pathways leading to a growing polymer chain carrying methyl groups in $(\gamma \alpha)(\gamma \alpha),(\gamma \alpha)(\alpha \gamma)$, $(\alpha \gamma)(\gamma \alpha)$ or $(\alpha \gamma)(\alpha \gamma)$ positions are competitive from a thermodynamic and kinetic point of view. 
In agreement with both a previous work on unsubstituted 7CC and TMC ROP mediated by $\left[\left(\mathrm{BDI}^{\mathrm{iPr}}\right) \mathrm{Zn}(\mathrm{OMe})\right]$ and experimental observations made with this catalyst system, ${ }^{6,8} 7 \mathrm{CC}-\gamma(R)$ is computed to be more easily polymerisable than TMC- $\gamma(R)$. From a thermodynamic point of view, the reaction is more favourable for $7 \mathrm{CC}-\gamma(R)$ (exergonic process) than for TMC- $\gamma(R)$ (almost athermic). From a kinetic point of view, in both cases, the rate-determining step to the ROP is the nucleophilic attack. However, the activation barrier corresponding to the overall ROP process, in particular for the first propagation step, is lower for 7CC- $\gamma(R)$ than for TMC- $\gamma(R)$ in agreement with the higher steric constraint induced by the growing polymer chain of a six member ring $(\mathrm{TMC}-\gamma(R)) v s$. that of a seven member ring $(7 \mathrm{CC}-\gamma(R))$.

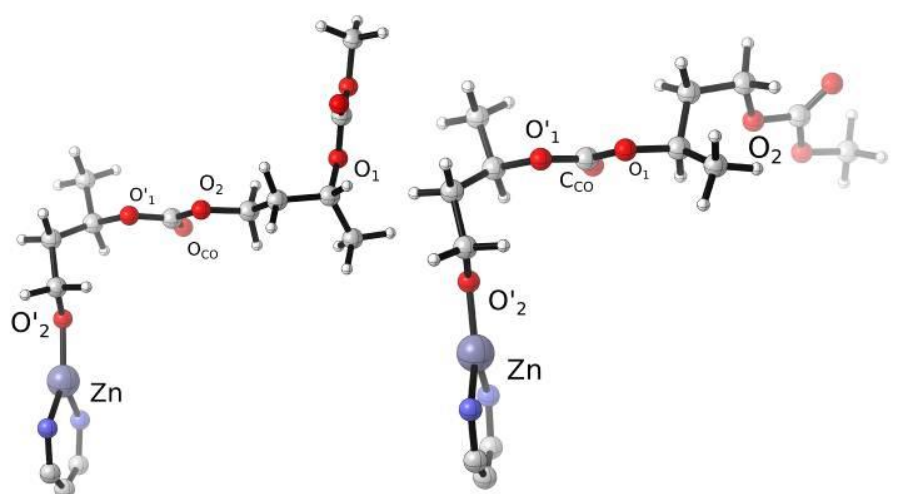

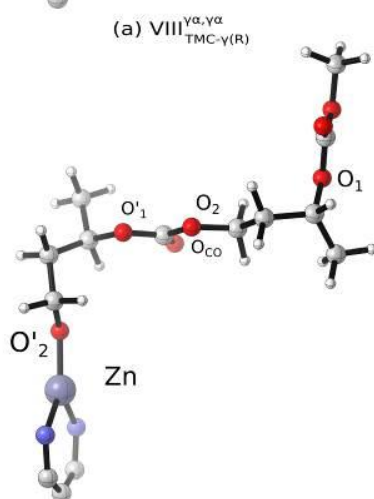

(c) VIIII TMC-Y(R)

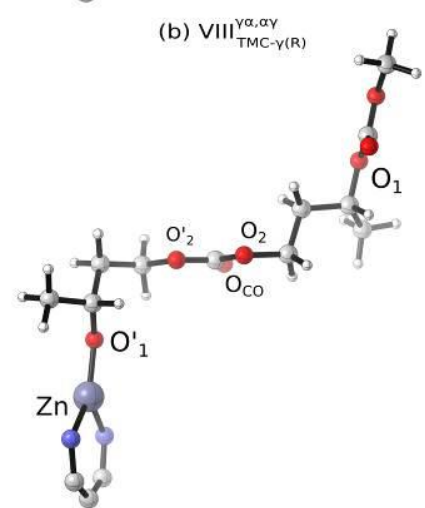

(d) VIII TMC.Y(R)

Figure 18. Optimized structures of the propagation products of the ROP of TMC- $\gamma(R)$ mediated by [(BDI $\left.\left.{ }^{\mathrm{iPr}}\right) \mathrm{Zn}(\mathrm{OMe})\right]$. In order to differentiate the two alkoxy oxygen atoms of the carbonate ester functional group, the oxygen atom closest to the substituted carbon atom is labelled $\mathrm{O}_{1}$; the other oxygen atom is then labelled $\mathrm{O}_{2}$. 


\section{Conclusions}

In this study, the first two steps of the ROP of 7CC- $\gamma \mathrm{Me}$ and TMC- $\gamma \mathrm{Me}$ mediated by an amido zinc $\beta$-diketiminate complex $\left[\left(\mathrm{BDI}^{\mathrm{iPr}}\right) \mathrm{Zn}\left(\mathrm{N}\left(\mathrm{SiMe}_{3}\right)_{2}\right)\right]$ precatalyst operating via a coordination-insertion mechanism have been studied using DFT methods. In order to catalyse the ROP process, $\left[\left(\mathrm{BDI}^{\mathrm{iPr}}\right) \mathrm{Zn}\left(\mathrm{N}\left(\mathrm{SiMe}_{3}\right)_{2}\right)\right]$ is first activated by alcoholysis of the $\mathrm{Zn}-\mathrm{N}$ bond by $\mathrm{HOBn}$ initiator, leading to the replacement of $\mathrm{N}\left(\mathrm{SiMe}_{3}\right)_{2}$ by an alkoxide $-\mathrm{OBn}$, with concomitant release of $\mathrm{HN}\left(\mathrm{SiMe}_{3}\right)_{2}$. For both $\gamma$-methyl substituted cyclic carbonates, it is shown that the initiation and the second insertion occur according to a three-step process: first, a nucleophilic attack of the alkoxide group followed by the ring-opening of the tetrahedral intermediate and finally the decoordination of the carbonate arm.

For both carbonates, these three steps are predicted to be kinetically accessible, both for the initiation and the propagation steps of the ROP process. The nucleophilic attack corresponds to the rate-limiting step. In agreement with a previous computational work on the related unsubstituted carbonate, ${ }^{8}$ the relaxation of the steric constraints inside the growing polymer chain appears to be an important feature. From a thermodynamic point of view, as also observed with unsubstituted carbonates, the overall polymerization process is exergonic (7CC- $\gamma \mathrm{Me}$ ) or almost athermic (TMC- $\gamma \mathrm{Me}$ ). However, the presence of the $\gamma$-methyl substituent induces some differences with respect to the unsubstituted analogues: (i) Due to the asymmetry induced by the presence of the $\gamma$-methyl substituent, two different products can be obtained upon cleavage of the acyl-oxygen bonds during the initiation step and four different products during the propagation step. Deeper insights into the preferred kinetic pathway for both methyl-substituted carbonates revealed, within the precision of the computational method, quite similar transition states from the nucleophilic attack. Thus, the four considered pathways are competitive from a thermodynamic and kinetic point of view.

(ii) The increase of the steric hindrance around the metal centre, induces an increase of the 34 
activation barriers of the first two steps of the second carbonate insertion, i.e., the nucleophilic attack and the ring-opening. (iii) In agreement with experimental results, for both carbonates, the relative Gibbs-free energies of the intermediates and the activation barriers involved in the ROP of both enantiomers are very close, in agreement with the formation of atactic polymers. On the other hand, computations indicate for both monomers preferential ring-opening at the most hindered oxygen-acyl $\mathrm{O}_{1}-\mathrm{C}(\mathrm{O}) \mathrm{O}$ bond, i.e. the one closest to the Me substituent, in agreement with the regioselectivities experimentally observed.

\section{Acknowledgements}

We are thankful to the Agence Nationale pour la Recherche (ANR) for financial support of the "BIOPOLYCAT" project (CP2D-08-01, Ph.D. grant to P.B.). CalMip (CNRS, Toulouse, France) and CINES (CNRS, Montpellier, France) are acknowledged for calculation facilities.

\section{References and Notes}

$\dagger$ Electronic Supplementary Information (ESI) available: Cartesian coordinates and free Gibbs energy for all transition states and intermediates.

1 a) J. Feng, R.-X. Zhuo and X.-Z. Zhang, Prog. Polym. Sci. 2012, 37, 211-236; b) H. Tian, Z. Tang, X. Zhuang and X. Chen, X. Jing, Prog. Polym. Sci. 2012, 37, 237-280; c) B. D. Ulery, L. S. Nair and C. T. Laurencin J. Polym. Sci., Part B: Polym. Phys., 2011, 49, 832864; d) D. J. A. Cameron and M. P. Shaver, Chem. Soc. Rev., 2011, 40, 1761-1776; e) T. Artham, M. Doble, Macromol. Biosci., 2008, 8, 14-24.

2 a) G. Rokicki and P.G. Parzuchowski, Polym. Sci. A Comprehensive Ref., 2012, 4, 247-307; b) S. Tempelaar, L. Mespouille, O. Coulembier, P. Dubois and A. P., Dove, Chem. Soc. Rev. 2013, 42,1312-36; c) L. Mespouille, O. Coulembier, M. Kawalec, A. P. Dove and P. Dubois, Prog. Polym. Sci., 2014, 39, 1144-64. 
3 a) J. J. Bozell and G. R. Petersen, Green Chem., 2010, 12, 539-554; b) C.-H. Zhou, J. N. Beltramini, Y.-X. Fan and G. Q. Lu, Chem. Soc. Rev., 2008, 37, 527-549; c) T. Werpy, G. Petersen, A. Aden, J. Bozell, J. Holladay, J. White and A. Manheim Results of Screening Potential Candidates from Sugars and Synthesis Gas, US DoE report, Washington, DC, 2004, vol. 1.

4 a) S. Tempelaar, L. Mespouille, O. Coulembier, P. Dubois and A. P. Dove, Chem. Soc. Rev., 2013, 42, 1322-1226; b) F. Suriano, O. Coulembier, J. L. Hedrick and P. Dubois, Polym. Chem., 2011, 2, 528-533.

5 a) N. Ajellal, J.-F. Carpentier, C. Guillaume, S. M. Guillaume, M. Helou, V. Poirier, Y. Sarazin and A. Trifonov, Dalton Trans., 2010, 39, 8363-8376; b) S. M. Guillaume and J.F. Carpentier, Catal. Sci. Tech., 2012, 2, 898-906.

6 a) P. Brignou, M. Gil Priebe, O. Casagrande, J.-F. Carpentier and S. M. Guillaume, Macromolecules, 2010, 43, 8007-8017; b) P. Brignou, J.-F. Carpentier and S. M. Guillaume, Macromolecules, 2011, 44, 5127-5135.

7 M. Helou, O. Miserque, J.-M. Brusson, J.-F. Carpentier and S. M. Guillaume, Polymer Chem., 2011, 2, $2789-2795$.

8 I. del Rosal, P. Brignou, S. M. Guillaume, J.-F. Carpentier and L. Maron, Polym. Chem., 2011, 2, 2564-2573.

9 M. J. Frisch et al. Gaussian 03 (Revision B.05), 2003.

10 a) A. D. Becke, Phys. Rev. A, 1988, 38, 3098-100. b) J. P. Perdew, in Electronic structure of solids'91; Ed. P. Ziesche, H. Eschrig (Akademie Verlag, Berlin), 1991. c) P. Perdew, J. A. Chevary, S. H. Vosko, K. A. Jackson, M. R. Pederson, D. J. Singh and C. Fiolhais, Phys. Rev. B, 1992, 46, 6671-87. d) J. P. Perdew, J. A. Chevary, S. H. Vosko, K. A. Jackson, M. R. Pederson, D. J. Singh and C. Fiolhais, Phys. Rev. B, 1993, 48, 4978. e) J. P. Perdew, K. Burke and Y. Wang, Phys. Rev. B, 1996, 54, 16533-16539. f) K. Burke, J. P. Perdew and Y. Wang, in Electronic Density Functional Theory: Recent Progress and New 
Directions, Ed. J. F. Dobson, G. Vignale and M. P. Das (Plenum, 1998); Chapter Derivation of a Generalized Gradient Approximation: the PW91 Density Functional.

11 D. Figgen, G. Rauhut, M. Dolg and H. Stoll, Chem. Phys., 2005, 311, 227-244.

12 a) R. Ditchfield, W. J. Hehre and J. A. Pople, J. Chem. Phys.,1971, 54, 724. b) W. J. Hehre, R. Ditchfield and J. A. Pople, J. Chem. Phys.,1972, 56, 2257. c) P. C. Hariharan and J. A. Pople, Theor. Chem. Acc., 1973, 28, 213-22. d) P. C. Hariharan and J. A. Pople, Mol. Phys., 1974, 27, 209-14. e) M. M. Francl, W. J. Pietro, W. J. Hehre, J. S. Binkley, D. J. DeFrees, J. A. Pople and M. S. Gordon, J. Chem. Phys., 1982, 77, 3654-65. f) T. Clark, J. Chandrasekhar, G. W. Spitznagel and P. v. R. Schleyer, J. Comp. Chem.,1983, 4, 294301. g) M. J. Frisch, J. A. Pople and J. S. Binkley, J. Chem. Phys., 1984, 80, 3265-69.

13 a) A. E. Reed and F. Weinhold, J. Chem. Phys., 1983, 78, 4066-4074. b) A. E. Reed, L. A. Curtiss and F. Weinhold, Chem. Rev., 1988, 88, 899-926.

14 a) C. M. Thomas, Chem. Soc. Rev., 2010, 39, 165-173. b) O. Dechy-Cabaret, B. MartinVaca and D. Bourissou, Chem. Rev., 2004, 104, 6147-6176.

15 Coates and coworkers have previously experimentally established that [(BDIiPr)Zn(OiPr)] $(\mathrm{BDIiPr}=2-((2,6$-diisopropylphenyl $)$ amido $)-4-((2,6$-diisopropylphenyl)-imino $)$-2-pentene $)$ resides primarily as a monomer in toluene- $\mathrm{d}_{8}$ solution under ROP conditions, despite forming a bis- $\mu$-alkoxide dimer in the solid state; such speciation in solution is essentially controlled by the bulky isopropyl groups on the aryl moieties of the BDI ligand (L. R. Rieth, D. R. Moore, E. B. Lobkovsky, and G W. Coates, J. Am. Chem. Soc., 2002, 124, 15239-15248; B. M. Chamberlain, M. Cheng, D. R. Moore, T. M. Ovitt, E. B. Lobkovsky and G. W. Coates, J. Am. Chem. Soc., 2001, 123, 3229-3238). Also, initiation of ROP of both lactide and $\beta$ butyrolactone with this complex has been shown to generate exclusively the corresponding mono-insertion product. Because of the well-documented, strong relationship between ROP of lactones, lactides and that of cyclic carbonates, it is also assumed that only monomeric 
(mononuclear) species are involved in our present study on cyclic carbonates. Accordingly, all computations have been performed on such monomeric species.

16 As well-established for coordination-insertion ROP processes similar to the one investigated in the present study, those ROP reactions essentially proceed in a living-like manner, apart from transesterification/transcarbonatation (reshuffling and back-biting) processes which are out of the scope of our investigations in this manuscript. (A. Buchard, C. M. Bakewell, J. Weiner, C. K. Williams, Topics in Organometallic Chemistry, Vol. 39: Organometallics and Renewables (Eds.: M. A. R. Meier, B. M. Weckhuysen, P. C. A. Bruijnincx), Springer-Verlag, Heidelberg, 2012, 175 - 224) Indeed, our work was rather aimed at understanding the reactivity, the regio- and stereo-selectivity of the initiation and propagation steps. In fact, termination/deactivation of ROP reactions occurs upon deliberate addition of a protic source (alcohol, water, Bronsted acid...) when quenching the reaction. The polymer formed is thus end-capped by the group introduced at this last stage or by the chain transfer agent introduced within our catalytic system (typically OBn/OMe in our case). Such end-group fidelity was evidenced in our prior experimental work. ${ }^{5,6}$ 17 Y. Zaho and D. G. Truhlar, Acc. Chem. Res., 2008, 41, 157-167. 